\title{
STRUT-AND-TIE COMPUTER MODELLING OF REINFORCED CONCRETE BRIDGE PORTAL FRAMES
}

\author{
N. H. T. TO ${ }^{1}$, J. M. INGHAM ${ }^{2}$ AND S. SRITHARAN ${ }^{3}$
}

\begin{abstract}
Nonlinear inelastic force-displacement response envelopes of full-scale reinforced concrete bridge portal frames are predicted in this paper by representing the frame using strut-and-tie models. The nonlinear strut-and-tie analyses, which included the tension stiffening effect, were performed using the computer program Drain-2DX. Strut-and-tie analytical results were found to correlate satisfactorily with the experimental data and to provide superior prediction to that generated using conventional planar frame models.
\end{abstract}

\subsection{INTRODUCTION}

Formulation of strut-and-tie models (STMs) of four largescale knee joint test units was presented in a companion paper [1]. Following validation of these STM models using experimentally observed data, this study examines predictions of the force-displacement response envelopes of full-scale reinforced concrete portal frames.

One full-scale experimental unit [2] and four prototype-scale reinforced concrete portal frames corresponding to an asbuilt, a repair, an externally post-tensioned retrofit and a redesigned unit were selected for the current study. Treatment of the knee joint, column and beam STMs has been extensively reported in References [1, 3 \& 4]. Applicable details, not previously considered, are presented in this paper. Modelling results reported herein demonstrated that the resulting force conditions in the struts and ties can be used to design or assess the critical structural members, such as beam-column knee joints.

\subsection{STM MEMBER AREA FOR CIRCULAR COLUMNS}

The companion paper [1] outlined a procedure to formulate suitable STMs for beams and for rectangular columns transversely reinforced by hoops or spirals. The procedure is extended in this paper to formulate STMs for circular columns. Typically, these structural members are located in Bernoulli (B-) regions, where a linear strain profile is assumed for the section, see Figure 1 .

\subsection{Longitudinal concrete strut and tie areas}

In this study, the cross-sectional area of concrete struts, $A_{c s}$, and concrete ties, $A_{c t}$, corresponding to the column flexural compression and tension zones are given by Eqs. 1a and $1 \mathrm{~b}$ :

$$
\begin{aligned}
& A_{c s}=\frac{D^{2}(\phi-\sin \phi \cos \phi)}{4} \\
& \text { where } \phi=\cos ^{-1}\left(\frac{0.5 D-c}{0.5 D}\right) \\
& A_{c t}=\frac{A_{g}-A_{c s}}{2}
\end{aligned}
$$

where $D$ is the total sectional diameter for circular sections or the total sectional depth for rectangular sections;

$\phi \quad$ is the half angle of the compression sector as defined in Figure $1 b$.

Note that the concrete tie area given in $\mathrm{Eq} . \mathrm{lb}$ corresponds to half of the actual area in the flexural tension zone. This selection was based on satisfactory correlation to the experimentally recorded uncracked unit stiffness. Furthermore, by assuming a linear strain profile as shown in Figure 1c, the maximum concrete flexural tension force can be accurately predicted by multiplying $A_{c t}$ by the effective tensile strength, whose computation is discussed below.

\subsection{Longitudinal reinforcement strut and tie areas}

For longitudinal reinforcement uniformly distributed inside the peripheral hoops or spirals, see Figure 1a, an analogous tube with a thickness, $t$, was assumed, see Figure $1 \mathrm{~b}$. Accordingly, the areas of the strut, $A_{r s}$, and tie, $A_{r}$, which represent the respective longitudinal compression and tension reinforcement, are computed as:

$$
\begin{aligned}
& A_{r s}=2(\pi-\alpha) \cdot t r_{o} \\
& A_{r t}=2 \alpha t r_{o} \\
& \text { where } \alpha=\cos ^{-1}\left(\frac{2 c-D}{D^{\prime}-d_{b}-d_{v s}}\right) \\
& t=\frac{A_{s t}}{2 \pi r_{o}}
\end{aligned}
$$

\footnotetext{
1 Doctoral Candidate, Department of Civil and Environmental Engineering, University of Auckland, New Zealand.

2 CCANZ Fellow, Department of Civil and Environmental Engineering, University of Auckland, New Zealand.

3 Assistant Professor, Department of Civil and Construction Engineering, Iowa State University, USA.
} 


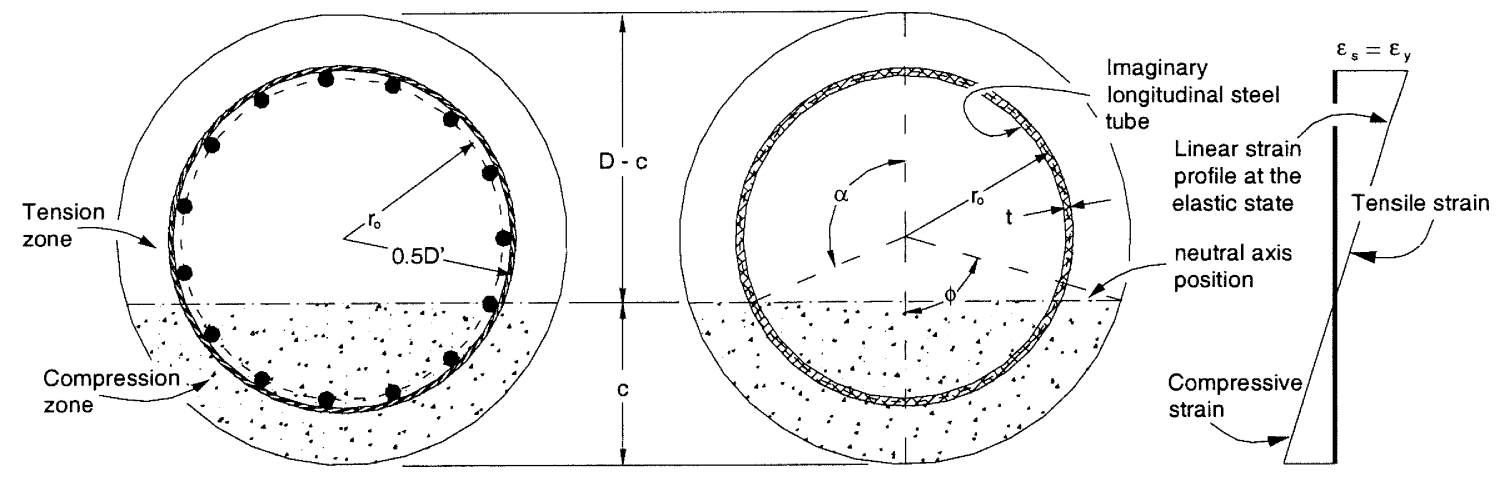

1a) Column section

1b) Equivalent column section

1c) Linear strain profile

Figure 1. A typical circular column section.

$$
r_{o}=\frac{D^{\prime}-d_{b}-d_{v s}}{2}
$$

where $\alpha$ is the half angle of tension sector shown in Fig. $1 \mathrm{~b}$;

$c$ is the neutral axis depth;

$D^{\prime}$ is the concrete core diameter measured from centre to centre of peripheral hoop or spiral;

$d_{b}$ is the longitudinal reinforcement bar diameter;

$d_{v s}$ is the sectional diameter of transverse reinforcement;

$t$ is the thickness of the steel tube representing the longitudinal reinforcement;

$r_{o}$ is the radius of the circular concrete core measured to the centreline of the longitudinal reinforcement;

$A_{s t}$ is the total area of longitudinal reinforcement.

\subsection{Diagonal concrete strut area}

The cross-sectional area of diagonal concrete struts, $A_{d c s}$, was computed by multiplying the perpendicular distance between the strut members, $h_{p}$, and an effective web width equal to $0.8 D$, see Figure 3a:

$A_{d c s}=0.8 h_{p} \cdot D$

The inclined angle between the strut and the longitudinal axis, $\theta$, was chosen in accordance with the limits suggested by CEB-FIP [5] of between $31^{\circ}$ and $59^{\circ}$, so as to permit an integer number of parallel diagonal struts.

\subsection{Transverse reinforcement tie area}

The nominal shear strength of a member, $V_{n}$, is the contribution of transverse reinforcement, $V_{s}$, concrete tensile strength, $V_{c}$, and the applied axial load, $V_{p}$. As significant concrete damage is anticipated inside the plastic hinge zone, the shear capacity attributed to concrete tensile strength, $V_{c}$, is expected to be minimal. Accordingly, the shear strength of members located outside and within the potential plastic hinge zone is computed using Eqs. $4 \mathrm{a}$ and $4 \mathrm{~b}$ respectively.

$V_{n}=V_{s}+V_{c}+V_{p} \quad$ outside the potential plastic

$V_{n}=V_{s}+V_{p}$

hinge zone

within the potential plastic

hinge zone
In the STM, the effective area of transverse tie, $A_{v}$, is subsequently computed as:

$$
A_{v}=\frac{V_{n}}{f_{v y}}
$$

where $f_{v y}$ is the measured yield strength of transverse reinforcement.

\subsubsection{Reinforcement contribution}

For columns transversely reinforced with circular hoops or spirals, the steel contribution to member shear strength, $V_{s}$, was computed using the proposed equation by Ang et al. [6], in conjunction with consideration of the inclined angle of diagonal concrete struts, to give:

$$
V_{s}=\frac{\pi D^{\prime}}{4 s \cdot \tan \theta} A_{v s} f_{v y}
$$

where $A_{v s}$ is the total area of transverse reinforcement in a layer in the direction of the shear force;

$f_{v y}$ is the tensile strength of transverse reinforcement;

$s$ is the longitudinal distance between transverse reinforcement.

\subsubsection{Concrete contribution}

The member shear strength attributed to the reinforced concrete tension capacity was computed using the modified compression field theory (MCFT) [7 \& 8] recommended by the Canadian Concrete Design Standard [9]. By taking account of the assumed diagonal crack angle, $\theta$, and the maximum longitudinal reinforcement tensile strain, $\varepsilon_{x}$, when computing the $\beta$ value, the concrete shear strength is given by:

$$
\begin{aligned}
& V_{c}=\beta \cdot \sqrt{f_{c}^{\prime}} \cdot A_{v e} \\
& \text { where } \beta=\frac{0.33 \cdot \cot \theta}{1+\sqrt{500 \cdot \varepsilon_{1}}} \leq \frac{0.18}{0.3+\left[\frac{7200 \varepsilon_{1}}{35}\right]} \\
& \varepsilon_{1}=\varepsilon_{x}+\left[\varepsilon_{x}+0.002 \cdot\right. \\
& \left.\quad\left(1-\sqrt{1-v \cdot\left(\tan \theta+\cot \theta\left(0.8+170 \varepsilon_{1}\right.\right.}\right)\right] \cdot \cot ^{2} \theta
\end{aligned}
$$




$$
\begin{aligned}
v & =\frac{V_{s}+V_{c}-V_{p r e}}{A_{v e} \cdot f_{c}^{\prime}} \\
A_{v e} & =0.628 D^{2}[10]
\end{aligned}
$$

where $\beta$ is the factor accounting for the shear resistance of cracked concrete;

$V_{\text {pre }}$ is the force component of prestress tendon in the direction of the applied shear;

$A_{v e}$ is the effective shear area;

$f_{c}^{\prime} \quad$ is the concrete cylinder strength, given in MPa.

$\varepsilon_{l}$ is the average principal tensile strain of diagonal concrete.

A trial-and-error computation procedure for determining concrete shear strength using MCFT is described below. Note that the procedure pre-requires knowledge of the maximum longitudinal reinforcement tensile strain, $\varepsilon_{x}$. In this study, this value was selected between upper and lower limits of $0 \leq \varepsilon_{x} \leq 0.002$, as recommended in Ref. [8]. The lower limit conservatively accounted for the situation when the member is subjected to high compression, such as in a partially prestressed section. The upper limit was determined assuming the quantity of provided longitudinal reinforcement to be sufficient to prevent yielding.

The upper limit of $\varepsilon_{x}$ derived from the no-yielding assumption is apparently contradictory to the condition in plastic hinge zones. As concrete shear capacity diminishes with increase in member ductility level [10], $V_{c}$ was ignored when computing the effective area of the transverse rebar tie in the potential plastic hinge zone, see Eq. $4 \mathrm{~b}$.

A rigorous equation to computed $\varepsilon_{x}$ is given in Refs. [7-9], however for simplicity, $\varepsilon_{x}$ can be selected from Table 1 according to the applied axial load levels.

The trial-and-error procedure for computing $\beta$ is as follows:

Step 1: Establish the appropriate inclined angle of diagonal concrete strut, $\theta$

Step 2: Calculate $V_{s}$ using Eq. 6.

Step 3: Select an $\varepsilon_{x}$ value from Table 1 according to the applied member axial load level.

Step 4: Guess the ratio of shear strength (excluding $V_{p}$ ): concrete cylinder strength, $v$.

Step 5: Solve the quadratic equation $7 \mathrm{c}$ to find $\varepsilon_{l}$.

Step 6: Compute $\beta$ using Eq. 7b.

Step 7: Calculate $V_{c}$ using Eq. $7 \mathrm{a}$.

Step 7 Calculate $v$ using Eq. $7 \mathrm{~d}$.

Step 8 Check if $v$ (derived in step 7) $=v$ (guess at step 2); Return to step 2 if necessary, otherwise obtain $V_{c}$.

Table 1. Determination of appropriate $\varepsilon_{\mathrm{x}}$ value.

\begin{tabular}{|c|c|}
\hline$\varepsilon_{x}$ & Axial load level $\left(N / A_{g} f_{C}^{\prime}\right)$ \\
\hline 0.0 & high \\
\hline 0.001 & moderate \\
\hline 0.002 & none \\
\hline
\end{tabular}

The procedure described above for computing the $\beta$ value usually converges rapidly when using an initial trial value of $v=0.1$. Furthermore, to assist in determining the $\beta$ value without solving the quadratic in Eq. $7 \mathrm{c}$, the design charts shown in Appendix B were plotted for different $v$ values as a function of $\theta$.

\subsubsection{Axial load contribution}

The contribution of member shear strength from axial load is considered as an independent component resulting from a diagonal compression strut:

$V_{p}=N \cdot \tan \alpha_{N}[10]$

where $N$ is the externally applied axial compression force (+ve) or axial tension force (-ve);

$\alpha_{N}$ is the angle between the column axis and the line joining the positions of concrete strut at the top and bottom of the column, see Figure $3 \mathrm{a}$.

\subsection{EFFECTIVE STRENGTH OF STRUT AND TIE MEMBERS}

Definitions for the effective strength of struts and ties representing the concrete and reinforcement, respectively, are discussed in this section.

\subsection{Concrete struts}

Eq. 9 was used to determine the effective strength of struts, $f_{d}$, representing the concrete flexural compression zones of structural members located in B-regions:

$f_{d}=\frac{C_{c(\max )}}{A_{c s}}$
where $C_{c(\text { max })}$

is the maximum concrete flexural compression force developed prior to failure, evaluated using section force analysis.

However as section force analysis is not available in disturbed (D-) regions, the effective strength of concrete struts located in D-regions was determined empirically as described in Ref. [1].

\subsection{Concrete ties}

Researchers [11 \& 12] have observed that the cracking strength of reinforced concrete members is different from the tensile strength of plain concrete due to the non-uniform concrete stress distribution induced by rebars orientated in both the longitudinal and transverse directions. Therefore, the plain concrete tensile strength is not appropriate for modelling the effective tensile strength of concrete ties.

In this study, the reinforced concrete ties that represent the concrete tension zones located in B- and D-regions, see Fig. $2 \mathrm{a}(\mathrm{i})$, are simplified by being depicted as reinforced concrete cylinder member that only carries uniaxial tensile stress, see Fig. $2 \mathrm{a}$ (ii). The effective strength of a concrete tie was then made identical to the cracking strength of this reinforced concrete cylinder member, which was computed using a trialand-error procedure. This procedure begins by guessing a 
tension capacity, $P$, of the reinforced concrete cylinder member and then calculating the transfer length, $\ell_{t}$, using Eqs. 10 and 11 [12]. The transfer length is the distance required for transferring the applied tension through the reinforcement to the surrounding concrete, see Fig. 2a(iii).

$$
\ell_{t}=k_{p} \frac{P}{(1+n \rho) \cdot \Sigma_{o}}
$$

where $n$ is the ratio of $E_{s} / E_{c}$;

$\rho$ is the area ratio of $A_{r t} / A_{c t}$

$\Sigma_{o}$ is the total perimeter of longitudinal rebar located in the flexural tension zone.

$k_{p}$ is a constant which was determined by Chan et al., [13] as:

$$
k_{p}=\frac{1}{u_{u l t}}
$$

$u_{u l t}=0.07467 \cdot\left(\frac{c_{c}}{2.5}\right)^{0.3} \cdot \frac{\sqrt{f_{c}^{\prime}}}{d_{b}}$

where $u_{u l t}$ is the ultimate bond stress between rebar and concrete;

$c_{c}$ is the concrete coverage to reinforcement;

$d_{b}$ is the rebar diameter;

An algorithm to describe the subsequent steps is illustrated in Figure $2 b$, in conjunction with Eqs. 10 to 13 . These equations were developed by Chan et al., [13] based upon the nonlinear piecewise functions of the bond stress between steel and concrete along a reinforced concrete member when subjected to direct tension, assuming no slippage of the reinforcement, see Fig. 2b.

Expressions to calculate the maximum and average concrete stresses for the different tension load levels are provided in Eqs. 12 and 13 as:

for $\ell_{t}<\ell^{\prime}$ :

$$
\begin{aligned}
& u_{m}=\frac{P}{0.4736 \Sigma_{o} \ell_{t} \cdot(1+n \rho)} \\
& \sigma_{c t}=\frac{0.4736 \Sigma_{o} u_{m} \ell_{t}}{A_{c t}} \\
& \bar{\sigma}_{c t}=\frac{\left(\ell^{\prime}-0.3408 \ell_{t}\right) \cdot P}{(1+n \rho) \cdot A_{c t} \ell^{\prime}} \\
& \text { for } \ell_{t}>\ell^{\prime}: \\
& \mathrm{a}=1.513 \ell^{\prime}-\frac{1.6565 P}{\Sigma_{o} u_{u l t} \cdot(1+n \rho)} \\
& \sigma_{c t}=\frac{0.9134 \Sigma_{o} u_{u l t} \ell^{\prime}}{A_{c t}}-\frac{0.6037 \Sigma_{o} u_{u l t} a}{A_{c t}} \\
& \bar{\sigma}_{c t}=\frac{0.4192 \Sigma_{o} u_{u l t} \ell^{\prime}}{A_{c t}}-\frac{0.2014 \Sigma_{o} u_{u l t} a^{2}}{A_{c t} \ell^{\prime}}
\end{aligned}
$$

where $\ell^{\prime} \quad$ is half of the tie member length, defined in Fig. $2 \mathrm{a}$ (ii).

$u_{m}$ is the maximum bond stress, defined in Fig. 2a(iii);

$a$ is the distance from member centre to the inner point of plateau of ultimate bond stress, see Fig. 2a(iv);

$\sigma_{c t}$ is the maximum reinforced concrete stress;

$\bar{\sigma}_{c t}$ is the average reinforced concrete stress.
The reinforced concrete cracking strength, $f_{c r}$, for both tension load levels was then calculated as:

$f_{c r}=0.92 f_{t}^{\prime} \cdot\left(\frac{\sigma_{c t}}{\bar{\sigma}_{c t}}\right)^{0.8}$

where $f_{t}^{\prime}$ is the plain concrete tensile strength, $=0.6 \checkmark f_{c}^{\prime}$ [14] for concrete subjected to flexural tension and $=0.5 \sqrt{ } f_{c}^{\prime}[10]$ for concrete subjected to direct tension.

Finally, the effective strength of concrete ties, $f_{d t}$, was assumed to be identical to the average reinforced concrete stress in a cylindrical member subjected to direct tension:

$f_{d t}=\bar{\sigma}_{c t}$

Note that the suggested procedure to calculate the effective tensile strength can be easily implemented using a spreadsheet.

To assist with determining the effective strength of concrete ties conveniently, the design charts shown in Appendix C were formulated for the reinforcement sizes commonly used in New Zealand. The effective strength of concrete ties, $f_{d t}$, given in these charts were normalised with respect to the plain concrete tensile strength, $f_{t}^{\prime}$, and were plotted for practical $\rho$ values as a function of $\ell^{\prime} / d_{b}$. Since $0.5 \leq c_{c} / d_{b} \leq 3$, where $c_{c}$ is the concrete coverage to reinforcement and $d_{b}$ is the rebar diameter, has minimal influence on the computed value of the effective strength of concrete ties, a practical value of $c_{c}=35 \mathrm{~mm}$ was adopted in the chart formulation. Moreover, for a section detailed with a uniform rebar size, the total perimeter of longitudinal rebar located in the flexural tension zone, $\Sigma_{o}$, is directly proportional to the tie area representing the longitudinal tension reinforcement, $A_{r}$ which is also incorporated in the $\rho$ parameter. Therefore computation of $\Sigma_{o}$ is not necessary when using these charts.

It is noted that the procedure described above for calculating the effective strength of concrete ties suggests no concrete cracking for the domain of $\ell^{\prime} / d_{b}$ smaller than that covered by the charts. As Chan's model assumes cracking to be initiated by the tensile stress in concrete, which is transferred from the embedded reinforcement through bond, a very short member inhabits transfer of sufficient tension to the concrete to induce cracking. For concrete ties having a member length shorter than that accounted for in the charts, cracking may still occur due to compatibility. In such cases, when located in B-regions, a linearly inclined stress distribution profile with an extreme tension fibre stress equal to $f_{t}^{\prime}$ was assumed. The effective tensile strength was then evaluated by dividing the total concrete tension force by the concrete tie area, $A_{c t}$, to give:

$$
\begin{aligned}
f_{d t} & =\frac{D^{2} f_{t}^{\prime}}{6 A_{c t}} \quad \text { for circular sections } \\
& =\frac{D \cdot b \cdot f_{t}^{\prime}}{4 A_{c t}} \quad \text { for rectangular sections } \\
& \text { where } f_{t}^{\prime}=0.6 \sqrt{f_{c}^{\prime}}[14]
\end{aligned}
$$$$
\text { and } b \text { is the total sectional width of rectangular sections. }
$$

For the short concrete ties located in D-regions, an empirical value of $f_{d t}=0.5 \sqrt{ } f_{c}^{\prime}[10]$ was employed in this study. 

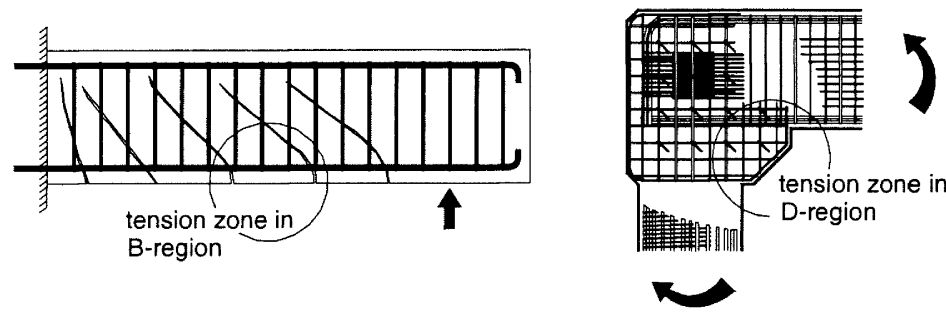

a (i) Tension zone in B- and D-regions.

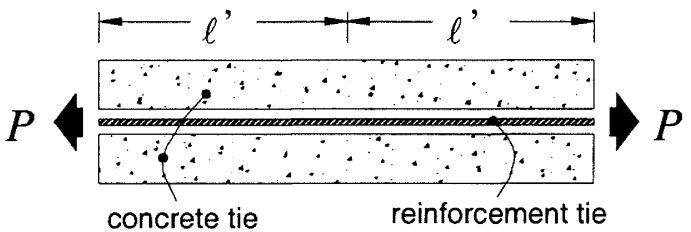

a (ii) Tie member representing the tension zone in B- or D-regions.

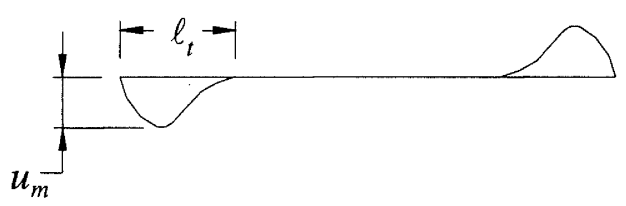

a (iii) Bond stress distribution when subjected to small tension forces.

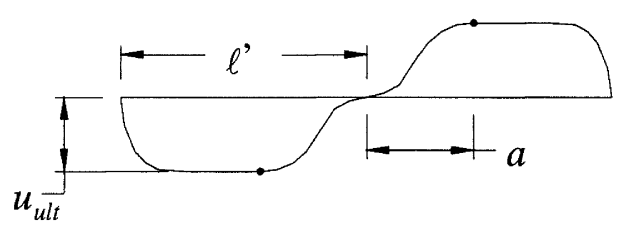

a (iv) Bond stress distribution when subjected to near ultimate tension forces.

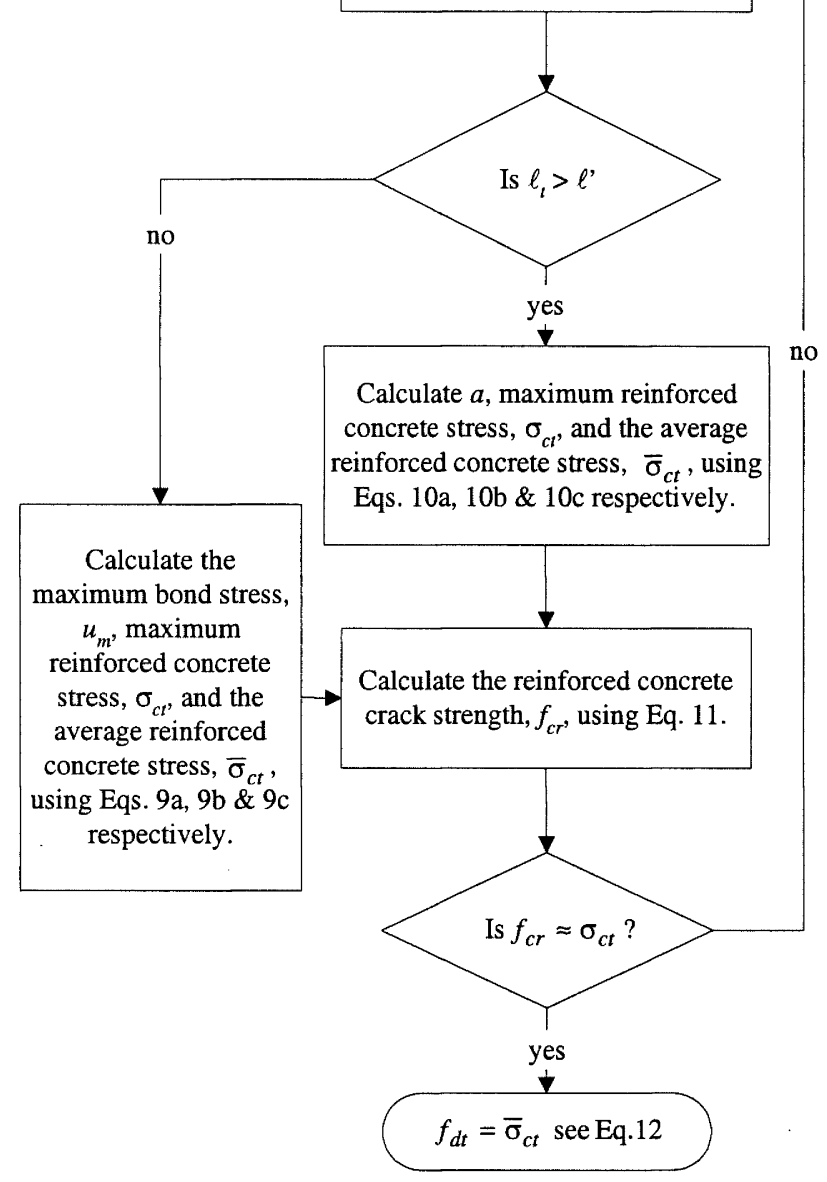

b) Algorithm to determine the concrete tie effective tensile strength.

Figure 2. Determining the effective strength of concrete ties.

\subsection{Reinforcement struts and ties}

For the circular column members located in B-regions, since a linear sectional strain profile is assumed, see Fig. 1c, the longitudinal reinforcement that is uniformly distributed within the peripheral transverse reinforcement does not sustain identical flexural stress. Therefore, the material yield strength is not suitable for modelling the effective strength of reinforcement struts, $f_{c y}$, and ties, $f_{t y}$. The appropriate effective strength values can be respectively obtained from Eqs. 17 and 18 as:

$$
f_{c y}=f_{y} \cdot \frac{\sin \alpha+(\pi-\alpha) \cos \alpha}{(\pi-\alpha) \cdot(1+\cos \alpha)}
$$

$$
\begin{aligned}
& f_{\text {ty }}=\phi_{o} \cdot f_{y} \cdot \frac{\sin \alpha-\alpha \cos \alpha}{2 \alpha \cos \left(\frac{\pi-\alpha}{2}\right) \cdot \sin \left(\pi-\frac{\alpha}{2}\right)} \\
& \text { where } f_{y} \begin{aligned}
\text { is the longitudinal reinforcement yield } \\
\text { strength. }
\end{aligned} \\
& \phi_{o}=4 / 3 \text { is the half angle of tension sector, see Fig. 1b. }
\end{aligned}
$$

\subsection{TENSION STIFFENING MODEL}

As a reinforced concrete member cracks, the intact concrete between cracks tends to rebound to the unstressed state but is 
restrained by the reinforcement, resulting in tensile stress in the concrete. The effect of the tension force carried by the intact concrete between adjacent cracks, known as tension stiffening, reduces the tension force carried by the reinforcement and thus indirectly increases stiffness.

The tension capacity of concrete is often neglected in the reinforced concrete design procedure since it does not generally influence the ultimate strength of the member. However tension stiffening needs to be accounted for when attempting to accurately predict the force-displacement response.

\subsection{Prakhya and Morley's model}

The tension stiffening model suggested by Prakhya and Morley [15], shown in Eq. 19, was used for modelling the stress-strain response of the cracked longitudinal concrete ties located in B- and D-regions. This model was derived from experimental studies $[16,17]$ of reinforced concrete beams and slabs that were subjected to short-term load.

Parameters that are employed in the model to govern the strength degradation branch include specific surface (i.e., the surface area of steel per unit volume of concrete, $s_{L}$ ), concrete coverage to the reinforcement, $c_{c}$, rebar spacing, $s_{R}$ and rebar diameter, $d_{b}$. This model was preferred because it considers the effect of reinforcement arrangement on the softening characteristic of reinforced concrete. Furthermore, the simplicity and versatility of the model allowed important features of material response to be replicated using the elements available in Drain-2DX. $f_{c t}=\frac{\beta_{t} f_{d t}\left(\frac{\varepsilon_{c t}}{\varepsilon_{d t}}\right)}{\beta_{t}-1+\left(\frac{\varepsilon_{c t}}{\varepsilon_{d t}}\right)^{\beta_{t}}}$ for $\varepsilon_{c t}>\varepsilon_{d t}$
$\beta_{t}=\left(\frac{100 A_{s t}}{A_{g}-A_{c s}}\right)^{0.366} \cdot\left(\frac{1}{s_{L} \cdot c_{c}}\right)^{0.344} \cdot\left(\frac{c_{c}}{s_{R}}\right)^{0.146}$

where $f_{c t}$ is the reinforced concrete stress;

$\varepsilon_{c t}$ is the reinforced concrete strain corresponding to $f_{c t}$;

$\varepsilon_{d t} \quad$ is the reinforced concrete strain corresponding to $f_{d t}$;

$\beta_{t} \geq 1$ is an empirical factor dictating the slope of the descending branch;

$A_{g}$ is the gross sectional area of structural members.

\subsection{STRESS-STRAIN CHARACTERISTICS OF STRUT AND TIE MEMBERS}

The force-displacement response of strut and tie members utilised in this study are illustrated in Fig. 3. The compressive stress-strain response of the concrete strut in Fig. $3 b$ is represented by a bilinear elastic-perfectly plastic curve. While the elastic branch of the curve is used to capture the elastic deformation of the concrete mass, the plastic branch is used to dictate the maximum allowable compression to be

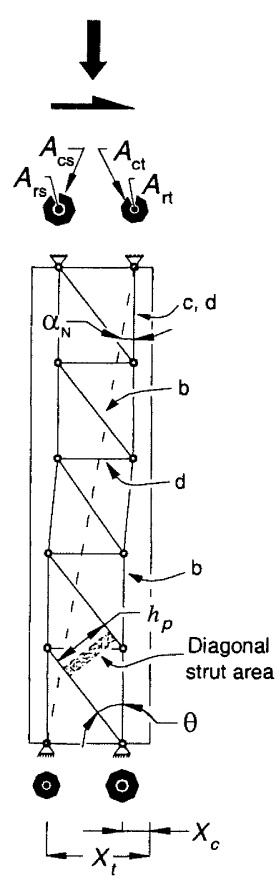

a, Column STM in double bending

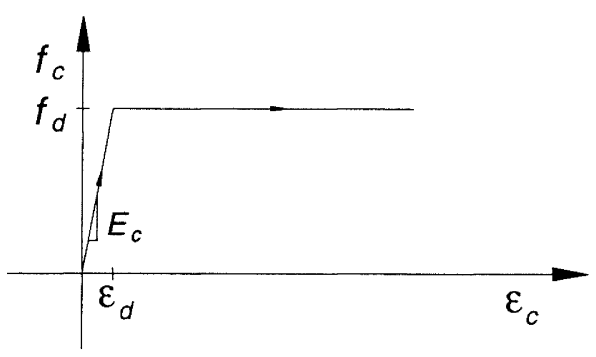

b, Longitudinal and Diagonal concrete strut subjected to compression

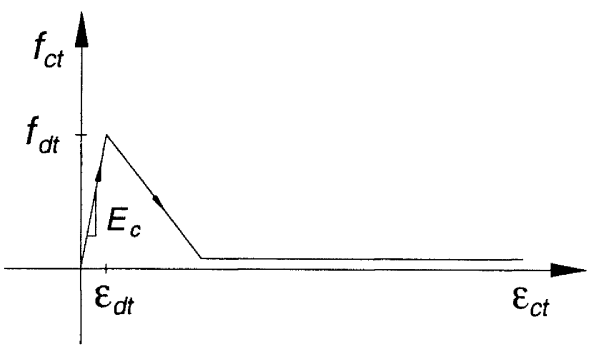

c, Longitudinal concrete tie subjected to tension

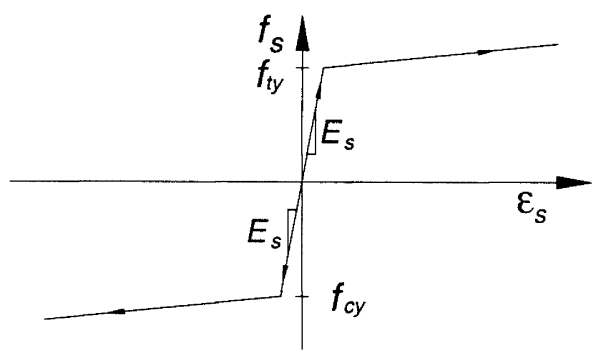

d, Reinforcement ties \& struts subjected to tension \& compression

Figure 3. Stress-strain characteristics of STM members. 
supported by the strut. The gradient of the elastic branch, $E_{c}$, was calculated using the suggested equation in Eurocode 2 [18]:

$$
\begin{aligned}
& E_{c}=9500 \cdot\left(f_{c}^{\prime}+8\right)^{0.33} \\
& \text { where } f_{c}^{\prime} \quad \text { is the concrete cylinder strength. }
\end{aligned}
$$

The tensile stress-strain characteristic of concrete ties is depicted in Figure $3 \mathrm{c}$ using a trilinear curve. The gradient of the ascending branch is identical to the concrete Youngs Modulus calculated using Eq. 20. The gradient of the descending branch and the residual strength were evaluated by approximating the trilinear representation to the aforementioned tension stiffening model in Eq. 19.

The stress-strain characteristic of ties representing reinforcement, when subjected to both tension and compression, was modelled using a bilinear curve shown in Fig. 3d. The commonly assumed Youngs Modulus, $E_{s}=200$ $\mathrm{GPa}$, was adopted as the gradient of the elastic branch and a strain hardening ratio (s.h.r.) was computed by a satisfactory correlation between the moment-curvature relationship evaluated using section force analysis and that exhibited by the STM. It was found the s.h.r. $=2.5 \%$ was appropriate for the ties or struts representing Grade 60 (413 MPa) longitudinal reinforcement located in columns and in beams having significant side reinforcement. Conversely, s.h.r. = $5 \%$ was found to be suitable for the ties and struts representing Grade 60 reinforcement located in beams without significant side reinforcement, and also for reinforcement located in D-regions.

The proposed s.h.r. values are also applicable to Grade 430 steel and Grade 500 steel. Grade 430 steel was commonly used in New Zealand until recently, but was replaced by Grade 500 steel from April 2002.

\subsection{DESIGN CHARTS}

For B-regions of structural members, the formulation procedure for the STM was established based upon section force analysis. Since analytical charts for beams and for rectangular columns that are transversely reinforced by hoops or spirals were presented in the companion paper [1], similar information is presented in Appendix D to assist formulating STMs for circular columns.

All analytical charts are presented for two different concrete strengths, $30 \mathrm{MPa}$ and $40 \mathrm{MPa}$, as a function of longitudinal reinforcement quantity, $\rho_{l}=A_{\mathrm{st}} / A_{\mathrm{g}}$, and axial load ratio, $N / f_{\mathrm{c}}^{\prime} A_{\mathrm{g}}$. The neutral axis depth, and compression and tension centroid positions evaluated at the first yield state were normalised with respect to the column diameter. The effective compressive strength of concrete struts was also normalised with respect to the concrete cylinder strength, $f_{\mathrm{c}}$. Discrete longitudinal reinforcement ratios were employed in the section force analysis, and continuous analytical charts were then developed by fitting the discrete points with smooth curves.

Grade 60 reinforcement, with respective nominal yield and ultimate strengths of $413 \mathrm{MPa}$ and $600 \mathrm{MPa}$, was assumed in the development of these charts. These charts can also be employed for Grade 430 steel, as insignificant discrepancy was observed. However, separate section force analyses are required for Grade 500 steel.

\subsection{CONVENTIONAL PLANAR FRAME ANALYSIS}

In conjunction with the STMs developed in this study, conventional planar frame models were also developed for comparison purposes. The procedure adopted for developing the planar frame models can be found in Ref. [1], with the exception of defining the effective flexural strength of

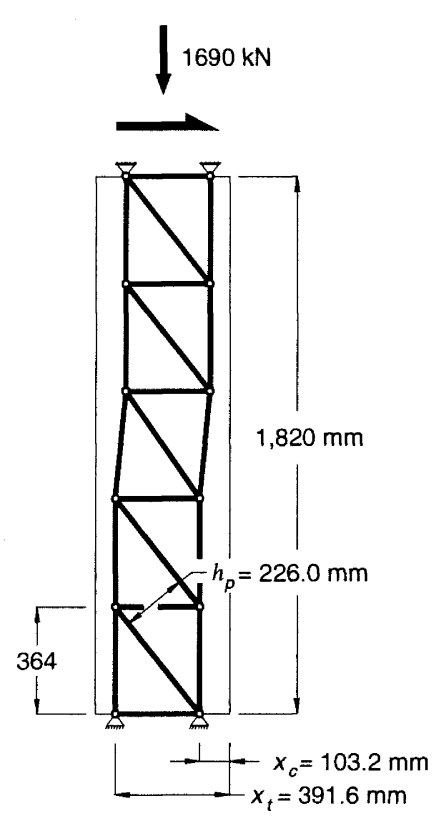

a) CS1 from Ref. [19]

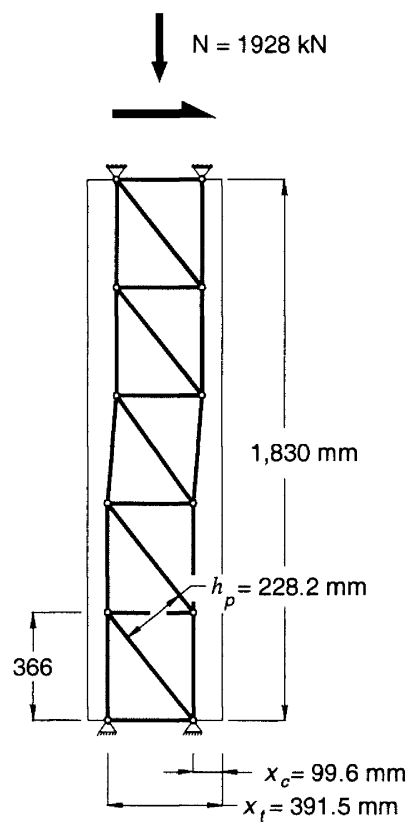

b) NH1 from Ref. [20]

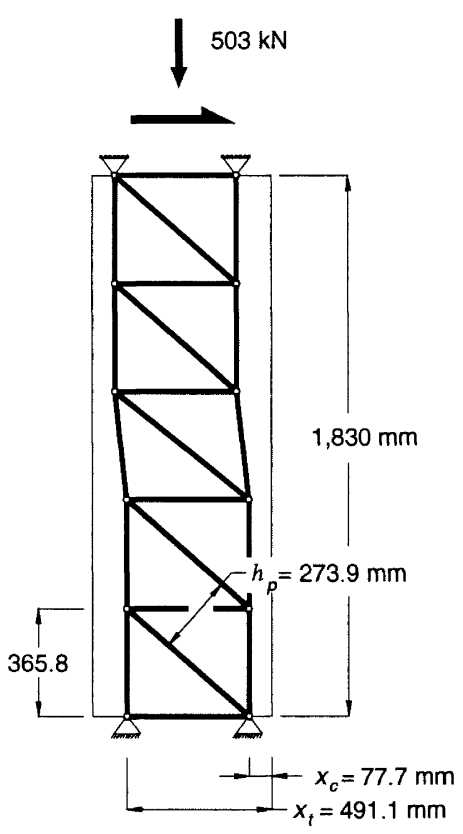

c) Column 1 from Ref. [21]

Figure 4. Column STMs. 
circular columns as $M_{e}=\phi_{o} \times M_{y}{ }^{1 s t}$ to improve correlation between analytical results and experimental data; where $\phi_{o}=$ $4 / 3$, and $M_{y}{ }^{I s t}$ is the first yield moment. The first yield moment state was defined by the commencement of tension rebar yielding or the extreme concrete compression fibre reaching a strain value of 0.002 , whichever occurred first. Based upon the moment-curvature relationship, it was found that s.h.r. $=2.5 \%$ and s.h.r. $=5 \%$ of the effective flexural stiffness are suitable for circular column and rectangular beam members respectively.

\subsection{STM EXAMPLES}

Formulation of STMs for circular columns, using the analytical charts in Appendix $\mathrm{C}$, is demonstrated using the column section depicted in the inset of Figure 5a [19]. This column had a diameter, $D=460 \mathrm{~mm}$, concrete cylinder strength, $f_{c}^{\prime}=30 \mathrm{MPa}$, a longitudinal reinforcement quantity, $\rho_{l}=0.025$ and an axial load ratio, $N / f_{\mathrm{c}} A_{\mathrm{g}}=0.35$. By following the dotted lines in Figs. D1, D3, D5 and D7 of Appendix $\mathrm{D}$, the neutral axis depth at the first-yield state, $c=$ $0.54 \mathrm{D}$, the compression centroid position $x_{c}=0.22 \mathrm{D}$, the tension centroid position, $x_{t}=0.86 D$ and the effective strength of concrete struts, $f_{d}$, was established to be $0.68 f_{\mathrm{c}}$. It should be noted that $x_{c}$ and $x_{t}$ are measured from the extreme compression fibre of the column section. The concrete core diameter, $D^{\prime}=423.2 \mathrm{~mm}$, and the diameter of longitudinal reinforcement, $d_{b}$, and transverse reinforcement, $d_{v s}$, were $15.9 \mathrm{~mm}$ and $6.35 \mathrm{~mm}$, respectively. From Eq. 1 the half angle of the compression sector was, $\phi=1.65 \mathrm{rad}$, which resulted in areas of concrete strut, $A_{c s}=91,900 \mathrm{~mm}^{2}$ and concrete tie, $A_{c t}=37,500 \mathrm{~mm}^{2}$. Using Eq. 2 , the half angle of the tension sector, $\alpha=1.48 \mathrm{rad}$, the radius of circular concrete core, $r_{o}=200.5 \mathrm{~mm}$ and the thickness of the steel tube, $t=3.14 \mathrm{~mm}$ were also found. The area of the strut representing longitudinal compression reinforcement, $A_{r s}=$ $2,100 \mathrm{~mm}^{2}$ and of the tie representing longitudinal tension reinforcement, $A_{r t}=1,860 \mathrm{~mm}^{2}$ were then calculated using Eqs. $2 \mathrm{a}$ and $2 \mathrm{~b}$ respectively. The column shear strength within and outside the potential plastic hinge zone was calculated to be $V_{n}=340 \mathrm{kN}$ and $V_{n}=649 \mathrm{kN}$ respectively, using Eqs. $4 \&$ 6-8. Accordingly, the effective areas of transverse rebar tie calculated using Eq. 5 for the members located outside and within the potential plastic hinge zone were $A_{v}=1,760 \mathrm{~mm}^{2}$ and $A_{v}=922 \mathrm{~mm}^{2}$ respectively. Finally, the tensile strength of concrete ties, $f_{d t}=2.85 \mathrm{MPa}$, the effective strength of longitudinal reinforcement struts, $f_{s y}$ $=0.63 f_{y}$ and the effective strength of longitudinal reinforcement ties, $f_{t y}=0.80 f_{y}$ were determined using Eq. 17 and Eq. 18 , respectively.

Also based upon section force analysis, the conventional planar frame model of the same column has effective flexural strength, $M_{e}=430 \mathrm{kNm}$, effective flexural stiffness, $E I_{e}=39$ $\mathrm{MNm}^{2}$ and effective axial stiffness, $E A_{e}=2,970 \mathrm{MN}$.

The formulated STM of column CS1 [19] is depicted in Fig. 4a. Analytical results derived from the STM in the positive force direction, i.e. force applied from left to right, were compared with the experimentally observed values shown in Fig. 5a. Results were also transposed to the negative quadrant for correlation. Comparison suggests a satisfactory prediction

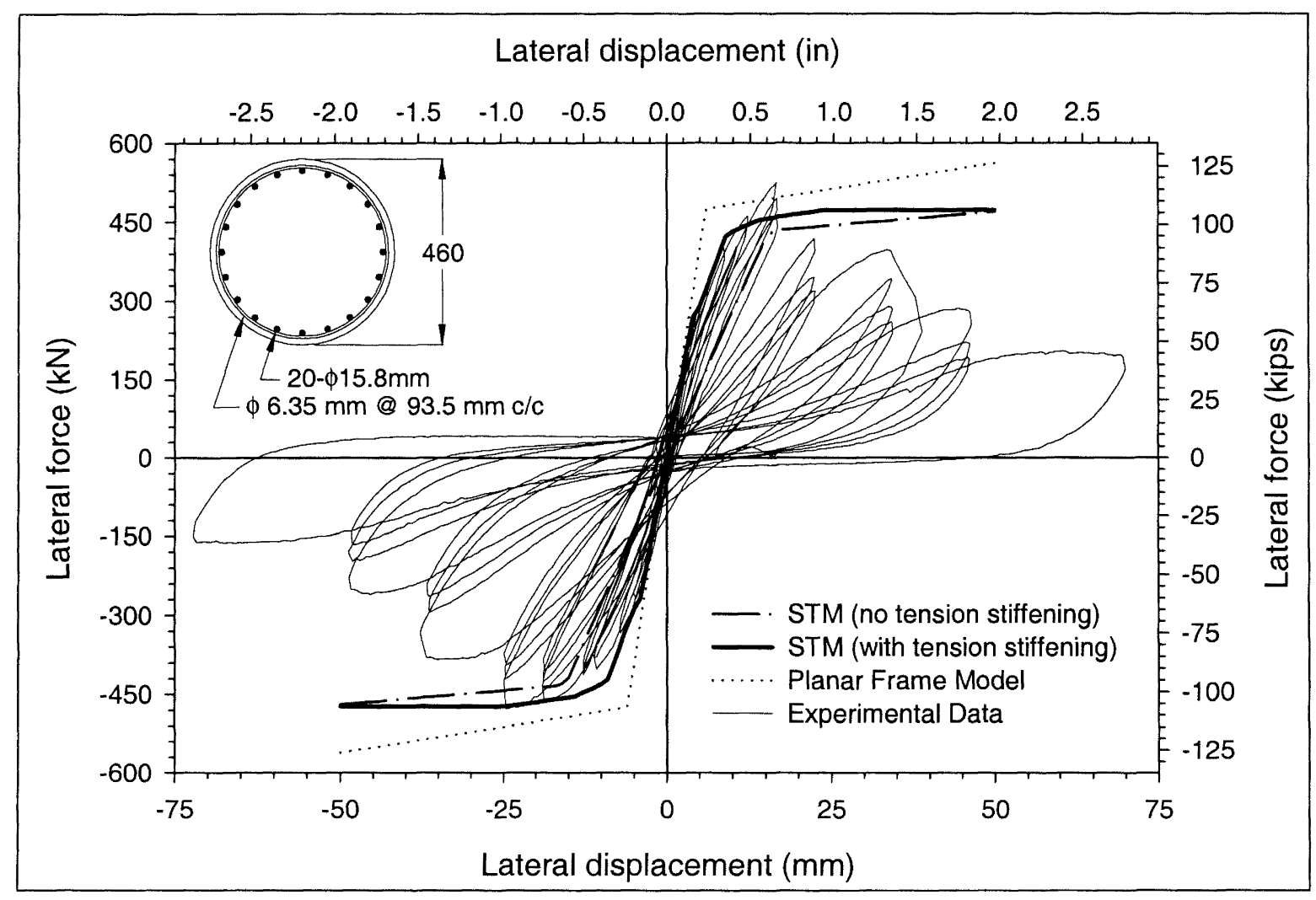

5a) Force-displacement history of the first circular column subjected to double bending [19], CS1.

Figure 5. Force-displacement correlation diagrams. 


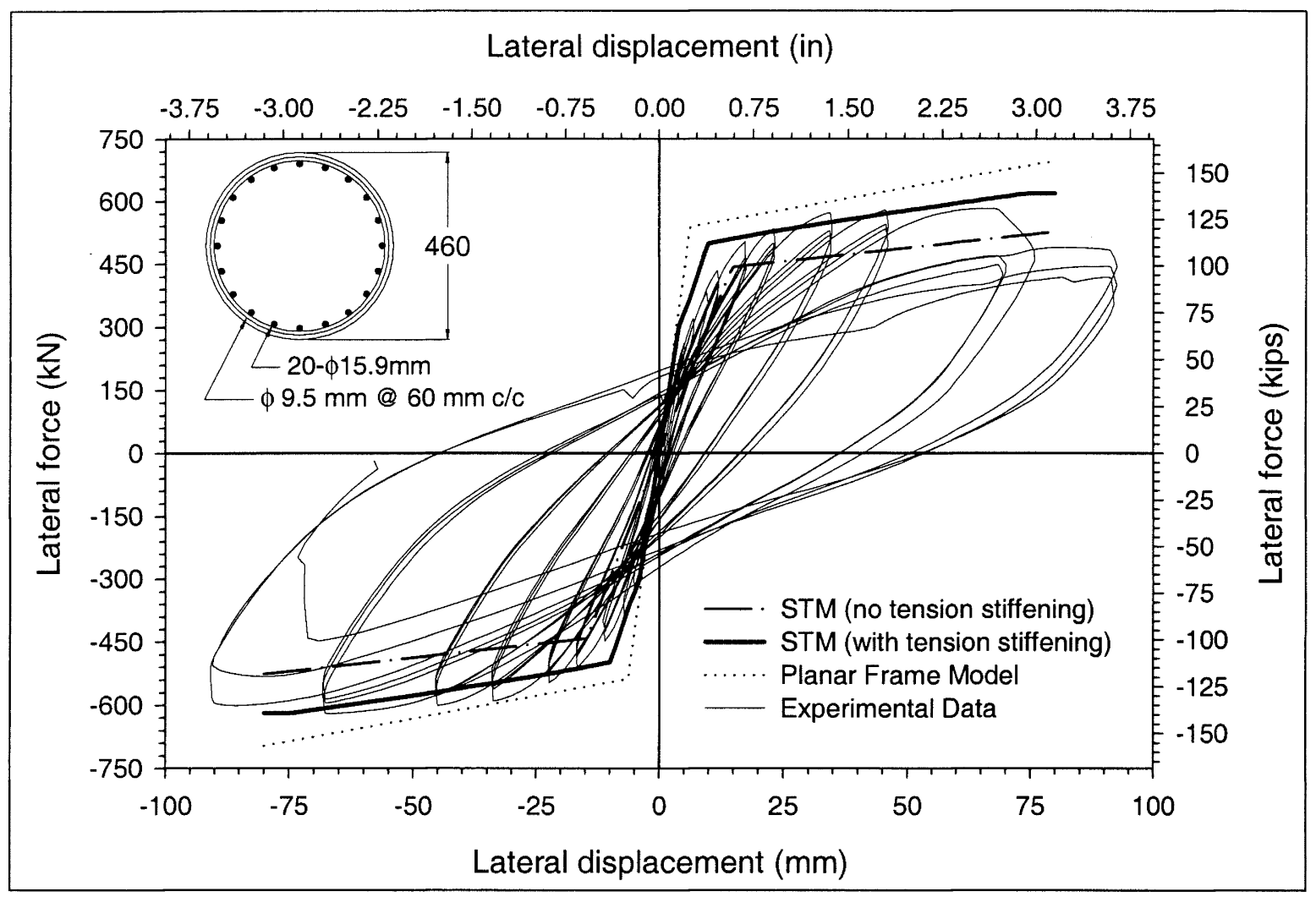

5b) Force-displacement history of the second circular column subjected to double bending [20], NH1.

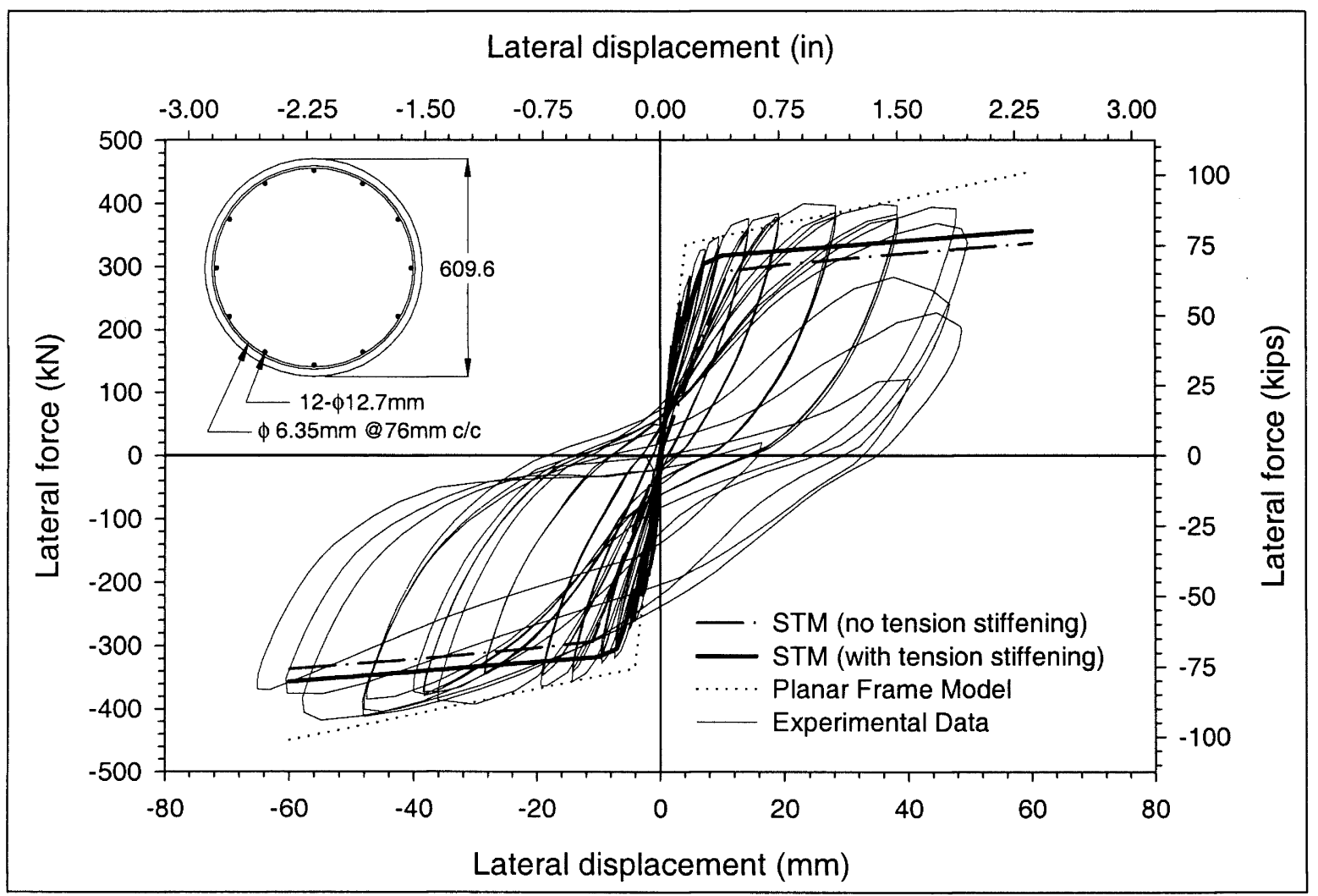

5c) Force-displacement history of the third circular column subjected to double bending [21], Column 1. 
of both elastic stiffness and maximum unit lateral strength. Analysis predicted that shear failure occurred at the lateral load level of approximately $425 \mathrm{kN}$ and the column base reached its full capacity at $455 \mathrm{kN}$, implying concrete spalling. As the test column was lightly transversely reinforced, spalling of concrete subsequent to transverse rebar yielding may be interpreted as the unit having approached the onset of drastic strength degradation.

Analytical results are consistent with experimental observations except that the shear strength degradation exhibited in the recorded force-displacement response was not captured due to limitations of the analytical computer program. The force-displacement response envelope generated using the planar frame model is also illustrated in Figure 5a. The effective flexural stiffness and the maximum unit lateral strength were captured satisfactorily.

The strut-and-tie analytical results derived from the model having no longitudinal concrete ties to simulate the tension stiffening effect are also shown in Fig. 5a. Since these modelling results indicate a less accurate prediction of elastic stiffness and unit lateral strength, modelling using this procedure is not recommended.

The same formulation procedures were utilised to develop the STMs and the planar frame models for two additional column members $[20,21]$, see Figs. $4 \mathrm{~b}$ and $4 \mathrm{c}$. Analytical results obtained from both modelling types are shown in Figs. $5 \mathrm{~b}$ and $5 \mathrm{c}$, accompanied by the test data. In general, both modelling types captured the column elastic stiffness and the unit lateral strength. However, cracking of concrete ties in the STMs incorporating tension stiffening facilitated stiffness softening in the elastic regime, resulting in superior prediction of force-displacement response when compared to that derived using the conventional planar frame models.

\subsection{REINFORCED CONCRETE PORTAL FRAME MODELS}

\subsection{Portal frame test unit}

As a direct extension of the previously-developed STMs of large scale knee joint test units $[1,4]$, this section reports five reinforced concrete portal frames that were analysed using the strut-and-tie methodology. Analytical results were compared with those generated using conventional planar frame models, as well as with experimental data for one frame.

The reinforcement details and the geometric configuration of the first portal frame are illustrated in Fig. 6a. This test unit consisted of circular columns and a rectangular beam, which were constructed in accordance with the as-built details of the multi-column bridge bent of the I10 Santa Monica Viaduct in Los Angeles, California [2]. Test results indicated that the first signs of significant shear cracking in both joints occurred at displacement ductility $\mu=1$ ( $\pm 42 \mathrm{~mm}$ ). Further concrete cracking occurred in both joints and both columns

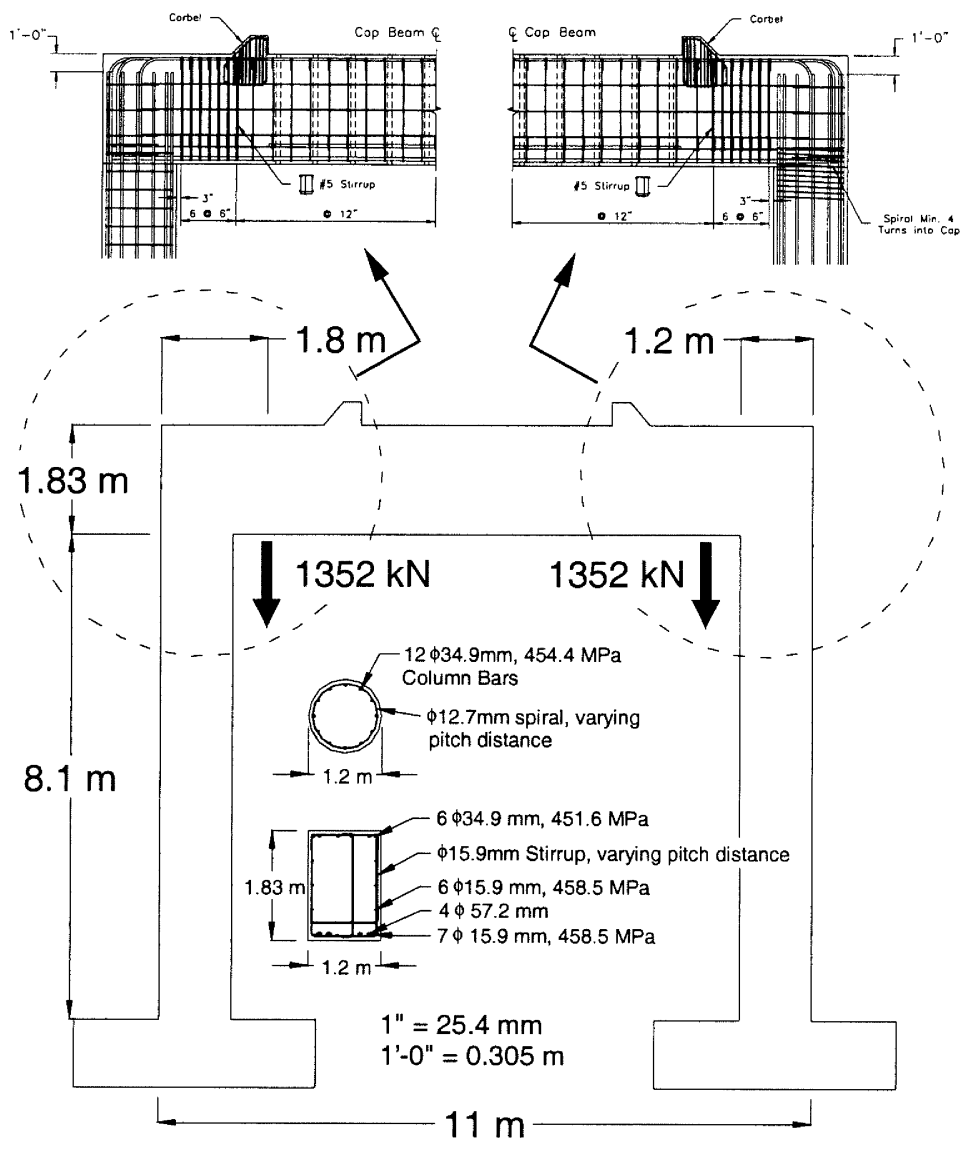

a, Elevations and reinforcement detail of Test Specimen.

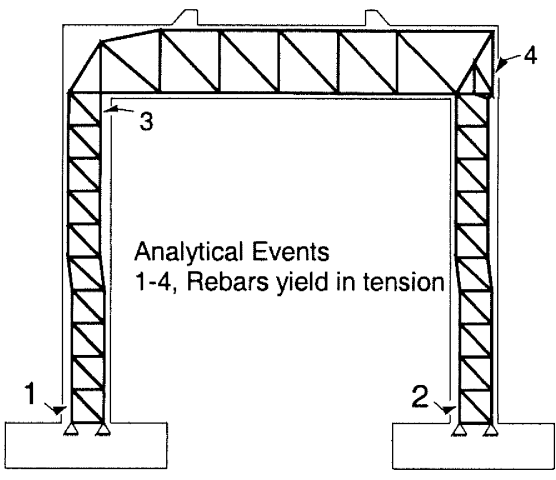

b, STM

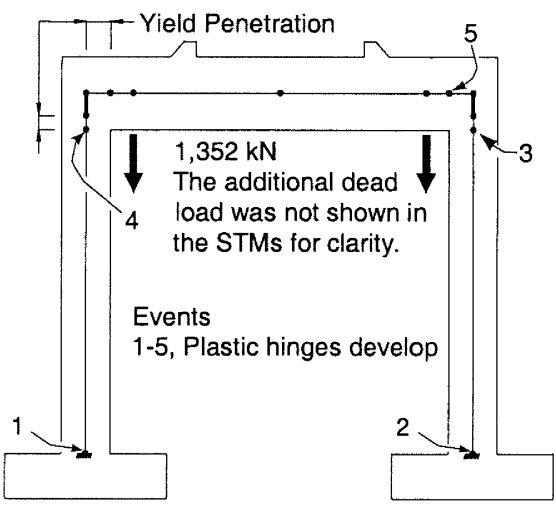

c, Conventional planar frame model

Figure 6. Test portal frame details and corresponding analytical model. 


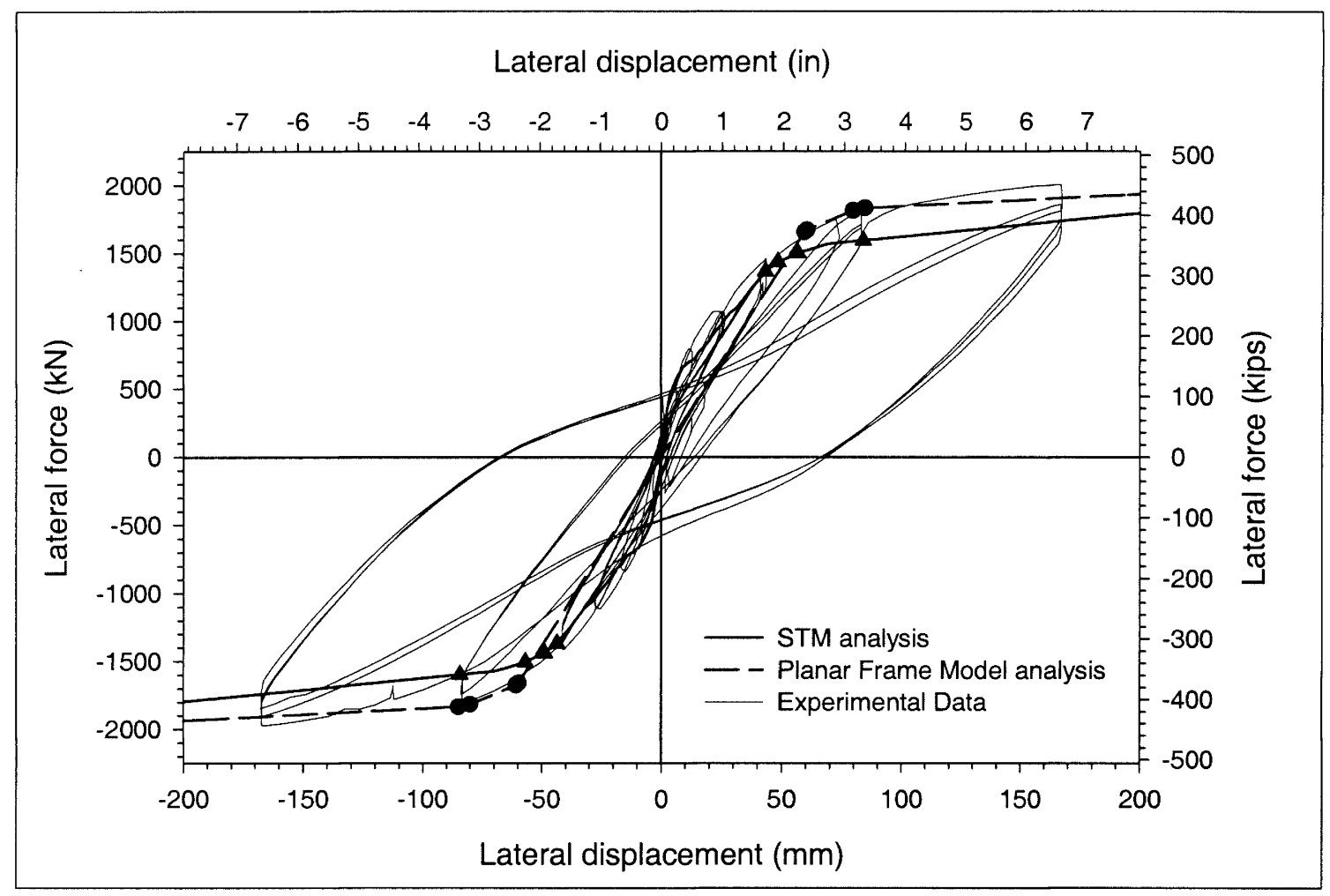

Figure 7. Correlation between test unit data and model response of the portal frame unit.

Table 2. Effective member properties for planar frame analyses.

\begin{tabular}{|c|c|c|c|}
\hline Members & $\frac{E I_{e}}{E I_{g}}$ & $\begin{array}{c}E I_{e} \\
\left(M N m^{2}\right)\end{array}$ & $E A_{e}(M N)$ \\
\hline $\begin{array}{l}\text { Test unit portal frame } \\
\text { column }\end{array}$ & 0.218 & 831.8 & 8953.4 \\
\hline $\begin{array}{l}\text { Test unit portal frame, +ve } \\
\text { beam property }\end{array}$ & 0.237 & 5267.2 & 18898.5 \\
\hline $\begin{array}{l}\text { Test unit portal frame, -ve } \\
\text { beam property }\end{array}$ & 0.132 & 2938.0 & 10541.4 \\
\hline $\begin{array}{l}\text { As-built and repair portal } \\
\text { frame column property }\end{array}$ & 0.381 & 15715.8 & 40119.0 \\
\hline $\begin{array}{l}\text { As-built and repair portal } \\
\text { frame column base }\end{array}$ & 0.112 & 587.2 & 6136.3 \\
\hline $\begin{array}{l}\text { As-built and repair portal } \\
\text { frame, +ve beam property }\end{array}$ & 0.210 & 12361.5 & 24995.9 \\
\hline $\begin{array}{l}\text { As-built and repair portal } \\
\text { frame, -ve beam property }\end{array}$ & 0.351 & 20676.6 & 41706.9 \\
\hline $\begin{array}{l}\text { Retrofit portal frame } \\
\text { column property }\end{array}$ & 0.354 & 16527.2 & 42193.1 \\
\hline $\begin{array}{l}\text { Retrofit portal frame } \\
\text { column base }\end{array}$ & 0.1003 & 591.2 & 6178.9 \\
\hline $\begin{array}{l}\text { Retrofit portal frame, +ve } \\
\text { beam property }\end{array}$ & 0.1652 & 13994.6 & 28246.5 \\
\hline $\begin{array}{l}\text { Retrofit portal frame, -ve } \\
\text { beam property }\end{array}$ & 0.361 & 30557.8 & 61643.0 \\
\hline $\begin{array}{l}\text { Redesign portal frame } \\
\text { column property }\end{array}$ & 0.382 & 17340.2 & 44268.3 \\
\hline $\begin{array}{c}\text { Redesign portal frame } \\
\text { column base }\end{array}$ & 0.113 & 646.8 & 6759.7 \\
\hline $\begin{array}{c}\text { Redesign portal frame, +ve } \\
\text { beam property }\end{array}$ & 0.324 & 30332.7 & 61188.9 \\
\hline $\begin{array}{l}\text { Redesign portal frame, -ve } \\
\text { beam property }\end{array}$ & 0.272 & 25461.0 & 51356.8 \\
\hline
\end{tabular}

below the joints associated with yield penetration of the column longitudinal reinforcement at displacement ductility $\mu=2$ ( $\pm 84 \mathrm{~mm})$. Also at this ductility level, "pull-out" failure of the bottom cap beam reinforcement was observed, resulting in less stable cyclic response beyond $\mu=2$, see Figure 7. Testing was terminated after 3 cycles at $\mu=4$, before significant strength degradation was observed, in order to preserve the integrity of the structure for the second phase of testing, which examined a retrofit solution. As the joint regions of the portal frame test unit were effectively unreinforced, simple joint-opening and joint-closing force transfer mechanisms, as documented in Refs. [1 \& 4], were utilised in formulating the model. In addition, the column reinforcement was terminated into the joint with straight bar end, indicating zero tension force at the top of the column reinforcement. Consequently, the beam compressive stress entering the joint-opening region was diverted, connecting with the reinforcement at a distance away from the bar end equal to half of the effective clamping length, $\ell_{c}$ :

$$
\ell_{c}=\frac{d_{b} f_{y}}{10 \sqrt{f_{c}^{\prime}}}
$$

As extensive concrete damage was anticipated in the joint regions due to the provision of only minimal reinforcement, $f_{d}=0.34 f_{c}^{\prime}$ [1] was adopted as the effective strength of concrete struts located in the joint panel regions. The STM is shown in Fig. $6 \mathrm{~b}$ for loads applied from left to right.

The STM analytical results are illustrated in Figure 7 using a solid line, accompanied by the experimentally observed values. Results were also transposed to the negative quadrant for comparison. Except for underestimation of the maximum unit lateral strength, the predicted force-displacement response envelope indicated satisfactory correlation between 
the analytical results and the experimental record, in particular for unit stiffness in the elastic regime.

Relevant analytical events captured by the STM are illustrated using solid triangles on the force-displacement response envelope shown in Figure 7. Analysis suggested that yielding of longitudinal reinforcement first occurred in the column bases as indicated by events 1 and 2 in Fig. 6 b. This was followed by yielding of longitudinal reinforcement located both below the opening-joint panel and adjacent to the closing-joint face, see events 3 and 4 in the same figure.

In general, the captured analytical events correlated satisfactorily with experimental observations, except that pull-out failure of the beam bottom reinforcement was not predicted because this aspect was not included in the STM model. Also, no concrete crushing in the joint regions was suggested by the STM analysis. Nevertheless, yielding of column longitudinal reinforcement located in the closingjoint region implied substantial cracking, as confirmed by testing.

The effective member properties of the planar frame model are listed in Table 2 and the obtained force-displacement response envelope is illustrated in Figure 7 using a dashed line. Analysis captured the maximum unit lateral strength but significantly underestimated the effective lateral stiffness. The formation sequence of plastic hinges captured by the planar frame model was, in general, consistent with that suggested by the STM, see events 1-4, except that the beam plasticity that developed next to the closing-joint, as indicated by event 5 in Figure $6 \mathrm{c}$, was not predicted in the STM.

\subsection{Prototype frame units}

Reinforced concrete portal frame STMs were developed analogous to the knee joint test units previously considered in the companion paper [1]. The geometric configuration of the prototype frames is illustrated in Figure 8. All frames consisted of a common rectangular column, which was transversely reinforced by interlocking circular spirals, but with different beam and joint reinforcement detailing types corresponding to an as-built, a repaired, an externally posttensioned retrofit and a redesigned unit. All prototype frames had column and beam sectional areas nine times that of the corresponding test units, and hence the reinforcement quantity was provided consistent with the geometric scale factor.

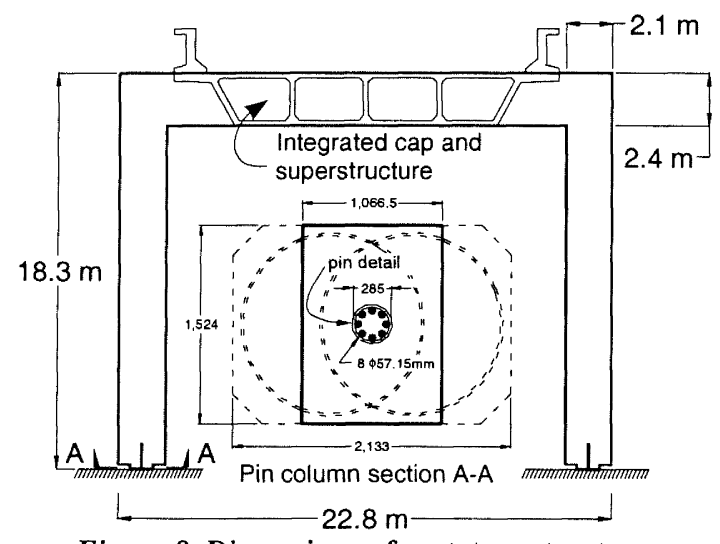

Figure 8. Dimensions of prototype structure.
All prototype portal frames were connected to the foundation using pin-based connections that were established by reducing the column to a sectional depth of $1,067 \mathrm{~mm}$, see Figure 8 . As this pin connection between column base and the foundation is not entirely moment resistance free, the actual moment resistance of the pin was also considered. The structural detail of the column base pin employed in all prototype frames is shown in the inset of Fig. 8. This detail was selected with reference to common practice and was achieved by connecting the column to the foundation with about $25 \%$ of the longitudinal reinforcement provided in the column. The reinforcement was located at the closest possible distance from the column centre to provide minimal flexural resistance, and sufficient vertical and horizontal connection. The integrated cap and superstructure connected to the beam were expected to have minimal flexural displacement, and were therefore modelled as rigid members in this study.

Prototype STMs were formulated for swaying to the right. Dead load was uniformly distributed to the members of the planar frame models but was resolved into equivalent nodal loads in the STMs. In all cases, STMs of the joint panel region were based on those previously documented in Ref. [4].

\subsubsection{Results for the as-built prototype frame}

The force-displacement response envelopes of the as-built prototype frame derived using both modelling types are illustrated in Figure 9a. For the STM, analysis predicted cracking in concrete ties commencing at a lateral load level of approximately $800 \mathrm{kN}$, leading to the softening of structural response in the elastic domain, followed by lap splice failure at an estimated lateral load level of $3100 \mathrm{kN}$. For the planar frame model, analysis indicated a full lateral strength of $3,450 \mathrm{kN}$ to be developed. As the planar frame model was unable to capture lap splice failure, it is assumed that the STM provided superior correlation.

Relevant analytical events derived from the STM are illustrated on the corresponding force-displacement response envelope using solid triangle in Fig. 9a. Analysis suggested that yielding of longitudinal reinforcement first occurred in the column base pin connections, see events 1 and 2 in the inset of Fig. 9a. This was followed by yielding of the beam longitudinal reinforcement embedded in and adjacent to the opening-joint region, see events 3 and 4 . Event 5 indicated lap splice failure of the reinforcement located adjacent to the face of the closing-joint panel, resulting in the sudden loss of structural strength. Subsequently, event 6 predicted concrete crushing in the joint region. Although the analysis suggested no further strength reduction following concrete crushing in the opening-joint panel due to the computational limitations of Drain-2DX, the structure is very likely to have become unstable when subjected to cyclic loading and it was assumed that structural failure would be imminent following event 6 .

Analytical events predicted by the planar frame model are depicted on the corresponding force-displacement response envelope using solid circles in Fig. 9a. Event 1 and 2, as illustrated in the inset of Fig. 9a, suggested that plastic hinges first developed at the column bases. This was followed by yielding in the beam member adjacent to the closing-joint 


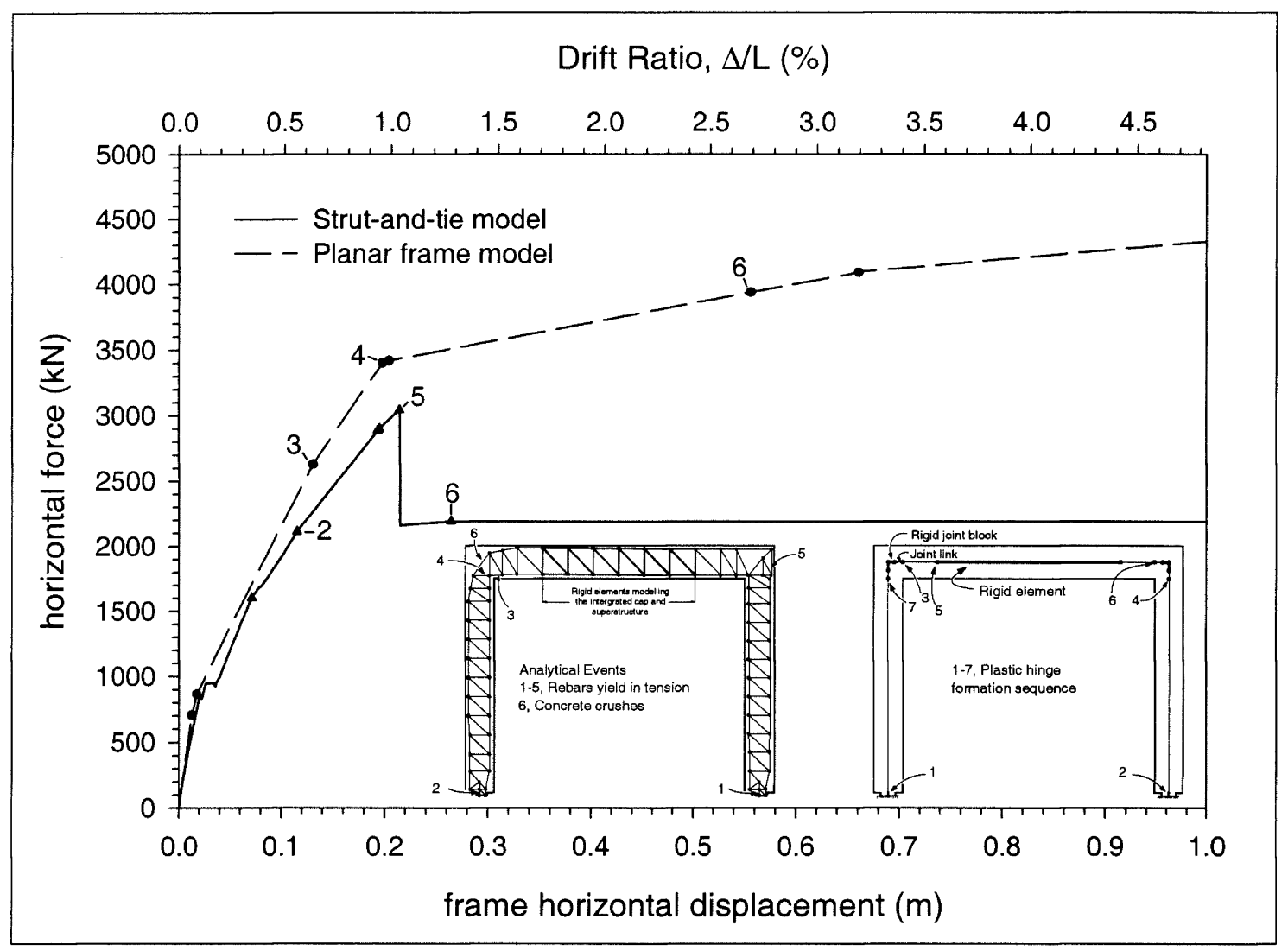

9a) Correlation diagram of the as-built prototype reinforced concrete portal frame.

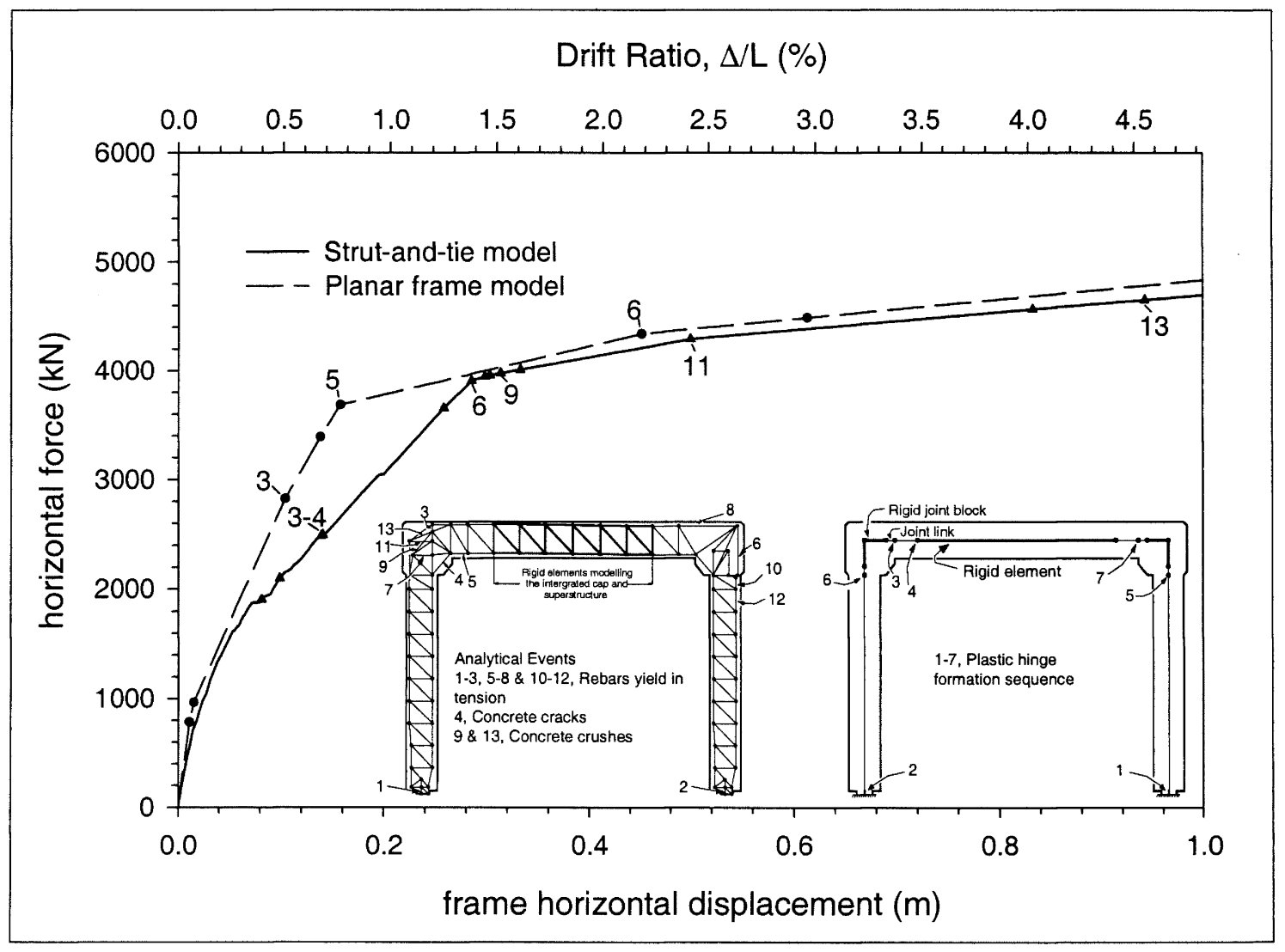

9b) Correlation diagram of the repaired prototype reinforced concrete portal frame.

Figure 9. The force-displacement response of prototype reinforced concrete portal frames. 


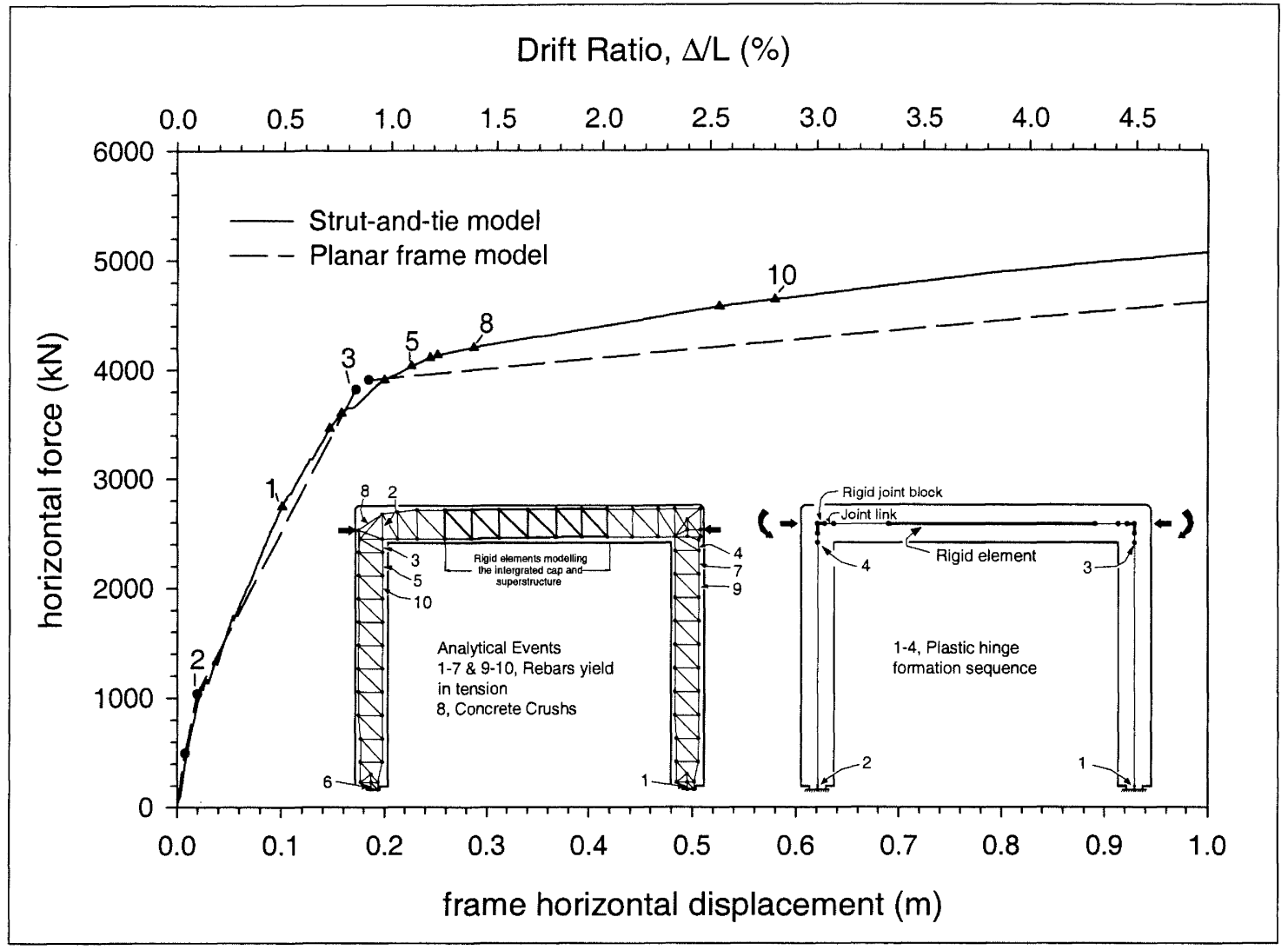

9c) Correlation diagram of the externally post-tensioned retrofitted prototype reinforced concrete portal frame.

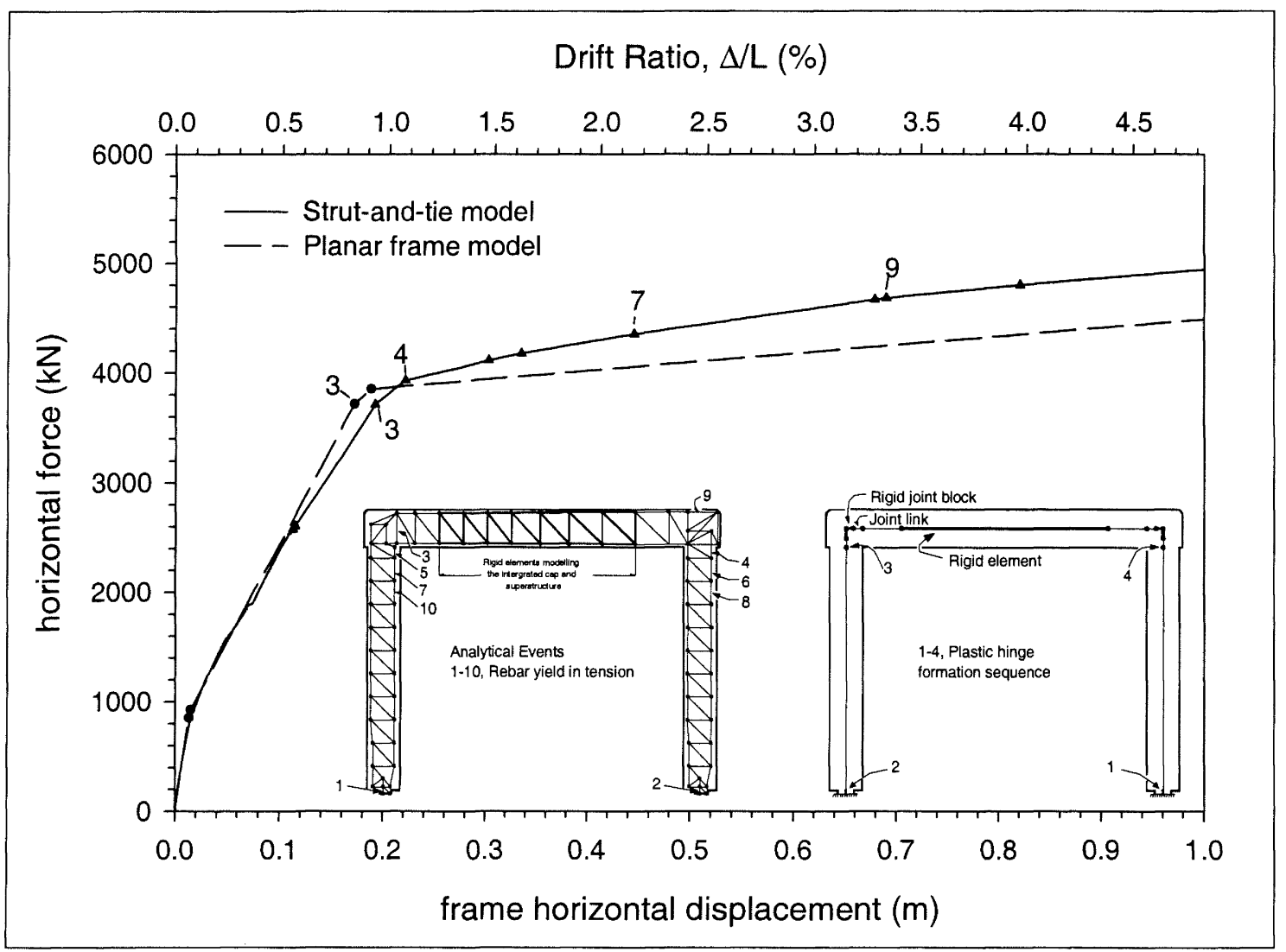

9d) Correlation diagram of the redesigned prototype reinforced concrete portal frame.

Figure 9. Continued. 
panel and below the opening-joint panel, see events 3 and 4 in the same figure. Event 5 indicated that a plastic hinge occurred in the beam member immediate left of the rigid element, suggesting the beam had significant flexural deformation when subjected to positive moment. This was expected since the beam was only lightly reinforced against positive flexure. Additional plastic hinges developed in the beam next to the closing-joint panel and in the column below the opening-joint panel, as suggested by events 6 and 7 respectively in the inset of Figure 9a.

\subsubsection{Results for the repaired prototype frame}

The repaired prototype frame shared the same column and beam members as the as-built unit, but the joint dimensions were increased by incorporating the joint haunch, and extra reinforcement was introduced to improve joint integrity.

The force-displacement response envelopes generated using both modelling types are illustrated in Figure 9b. Both response envelopes suggested similar structural strength but with significant discrepancy in the predicted elastic response. Crushing of concrete struts and yielding of joint reinforcement, resulting in the progressive softening of the frame elastic stiffness, was captured by the STM but was not identified in the planar frame analysis. Since joint performance did not influence the resultant forcedisplacement envelope derived using the planar frame model, it is believed that the STM analytical results correlate better with expected behaviour.

Relevant analytical results captured by the STM are illustrated on the corresponding force-displacement envelope using solid triangles. As suggested by events 1 and 2, shown in the inset of Fig. 9b, yielding of longitudinal reinforcement first occurred in the pin connections. This was followed by yielding of joint reinforcement, see event 3 , and by concrete cracking in the haunch of the opening-joint panel, see event 4. Subsequently, reinforcement yielding and concrete crushing occurred in both joints, see events 5-9, and a plastic hinge developed in the column below the closing-joint panel, see events 10 and 12. Further reinforcement yielding and concrete crushing in the opening-joint panel was captured by events 11 and 13 at a large displacement level.

For the planar frame model, analytical results are illustrated on the corresponding response envelope using solid circles. Events 1 and 2 depicted in the inset of Fig. 9b suggested that plastic hinges first developed at the column bases. This was followed by plastic hinge formulation located in the beam, adjacent to the opening-joint panel, see events 3 and 4 . This implied substantial flexural deformation in portion of the beam between the opening-joint panel and the rigid element. The model reaches its yield strength at event 5 , indicating the development of plasticity in the column member beneath the closing-joint panel. Additional plastic hinges subsequently developed at large lateral displacement levels in the column and in the beam, see events 6 and 7 in the inset of Figure $9 \mathrm{~b}$.

\subsubsection{Results for the retrofitted prototype frame}

The reinforcement details of the retrofitted unit were identical to those of the as-built unit. Consequently, the STM for the retrofitted prototype frame shown in the inset of
Figure 9c closely resembled that of the as-built frame, except that additional concrete struts were mobilised at both ends of the cap-beam to account for the effect of unbonded posttensioning.

The force-displacement response envelopes generated using the STM and the planar frame model are illustrated in Fig. $9 \mathrm{c}$. In contrast to the as-built and repaired prototype analyse, the two envelopes predicted very similar structural response for both stiffness and strength. This was because no joint damage was expected in the elastic regime, resulting in minimal elastic displacement attributable to joint deformations. Consequently, rigid joint behaviour, which was modelled in the STM, was similar to that assumed in the planar frame model. Indicated in the STM forcedisplacement response envelope is concrete cracking at a load level of approximately $1,150 \mathrm{kN}$, evident by the softer elastic stiffness response. The envelope also exhibited a smooth transition between the elastic and plastic domain as reinforcement yielding was sequentially captured by the STM.

Relevant analytical events captured using the STM are illustrated in Figure $9 \mathrm{c}$ on the corresponding forcedisplacement response envelope using solid triangles. Event 1 indicated that yielding of longitudinal reinforcement first occurred at the pin connection. This was followed by yielding of column longitudinal reinforcement below the joint regions in both columns, see events 2-5, 7 and 9-10 in the inset of Figure 9c. Analytical event 8 suggested concrete crushing in the opening-joint panel, indicating joint damage and possibly unstable cyclic response.

Analytical events captured using the planar frame model are illustrated on the corresponding force-displacement envelope using solid circles in Figure 9c. Results suggested that plastic hinges first developed in the column bases, see events 1 and 2 in the inset of Fig. 9c. As with the STM, the model reaches its yield strength when plastic hinges developed in both columns adjacent to the joint interface, see events 3 and 4 in the same figure.

\subsubsection{Results for the redesign prototype frame}

The redesign test unit had an identical column to the as-built unit, but was constructed with different beam and joint reinforcement details to enhance the positive flexural strength of the beam member and to ensure satisfactory behaviour of the joints.

The force-displacement response envelopes generated using the STM and the planar frame model are illustrated in Figure $9 \mathrm{~d}$. Similar to the retrofitted prototype frame, the two response envelopes indicated comparable lateral frame stiffness and strength. This was anticipated since joint integrity was ensured and plasticity was only expected to develop in the column members, resulting in column flexural deformation being primarily responsible for the frame lateral displacement. From the STM analysis, cracking of concrete commenced at a load level of approximately $1,500 \mathrm{kN}$, indicated by the softer elastic response. Also exhibited in the STM response envelope is the smooth transition between the elastic and the plastic domain as yielding of column longitudinal reinforcement was sequentially captured by the STM 
Relevant analytical events captured by the STM are illustrated on the corresponding force-displacement response envelope using solid triangle in Figure $9 \mathrm{~d}$. Captured by events 1 and 2, shown in the inset of Fig. 9d, are yielding of the longitudinal reinforcement in the pin connections. Events 3-8 and 10 indicated progressive yielding of longitudinal reinforcement located in the columns beneath both of the joint panel regions. Event 9 suggested that yielding developed in the top beam longitudinal reinforcement embedded in the closing-joint panel region.

Analytical events captured by the planar frame model are depicted on the corresponding response envelope using solid circles in Figure 9d. Results suggested member plasticity to be developed at similar locations to that predicted using the STM. Analysis indicated that plastic hinges first occurred at the column bases, see events 1 and 2 in the inset of Fig. 9d, followed by hinge in the columns below both of the joint panel regions, see events 3 and 4 in the same figure.

\subsubsection{Further comments on the structural performance of the prototype portal frames}

The following comments are made to summarise the performance of the prototype portal frames, based on conclusions derived from the STM analytical results.

Lateral strength of the as-built prototype portal frame was dictated by the lap splice capacity between the reinforcement located in the closing-joint region. Lap splice failure, as a result of significant concrete damage in the joint region or inadequate lap splice length between reinforcement, lead to unstable structural behaviour when the frame was subjected to earthquake loading. This behaviour was not captured using a typical planar frame model. Furthermore, predicted concrete crushing in the opening-joint region, subsequent to lap splice failure, could lead to catastrophic structural failure.

For the repaired prototype portal frame, STM model suggested that full unit lateral strength would be developed. However, extensive yielding of reinforcement and concrete crushing in the joint panel regions indicated that substantial joint damage would occur, which could not be diagnosed using the planar frame modelling technique. Moreover, the soft elastic response, leading to excessive elastic displacement, was undesirable at the serviceability limit state.

Comparing response of the retrofitted and redesigned prototype frames, it was apparent that the redesigned solution was preferred. This was because of the minimal joint damage and the member plasticity only developed in the column members, allowing ease of repair following an earthquake. Although the retrofitted design was susceptible to joint damage, it was regarded as an acceptable strengthening solution to the existing bridge frame due to the desirable elastic stiffness and the avoidance of premature structural failure.

\subsubsection{Comparison between Strut-and-Tie and Planar Frame Modelling Techniques}

When comparing the predicted force-displacement envelopes of the bridge portal frames generated using STMs and planar frame models, discrepancy exhibited between the two sets of corresponding results was particular apparent when joint performance dominated structural behaviour. This discrepancy was inevitable because in a planar frame model, the joint panels are represented by rigid members which prevent joint performance from being correctly investigated. In this regard, the STM is advantageous over the planar frame model as it can not only determine member strength, see Figure 5, but also capture strength degradation resulting from inferior joint performance, see Figures 9a \& 9b.

\subsection{CONCLUSIONS}

The study reported in the current research paper represents an attempt to develop a robust and simple STM formulation procedure which is capable of predicting the nonlinear inelastic response of reinforced concrete bridge frames. Within this study, the tension stiffening effect was investigated and suitable material constitutive models were incorporated into the STM formulation. A procedure to determine the effective tensile strength of concrete ties was also examined.

Three circular columns were analysed using STMs, which were formulated by considering the tension stiffening effect. Satisfactory correlation between the analytical inelastic force-displacement response envelopes and the actual measured values was observed.

As a direct extension of a study detailed in the companion paper [1], STMs were formulated in the current investigation to capture the inelastic force-displacement response envelopes of a large-scale portal frame test unit and four fullscale prototype portal frames. Analytical results obtained from STMs were compared with those generated using conventional planar frame models.

The STMs were found to provide superior predicted response to that obtained using conventional planar frame models in terms of stiffness, lateral strength and the expected damage to structural components. In contrast to the STM, analytical results obtained from the conventional planar frame model were less informative and in some cases, the behaviour of structural members located in D-regions were not accurately captured by the typical planar frame modelling technique.

Provided that a rational STM is employed in the analysis, the procedure is a useful tool in assisting designers to examine the capacity of structural components. However, it must be emphasised that the greater complexity of the model will likely impede application of the strut-and-tie methodology in design offices.

\section{ACKNOWLEDGEMENTS}

Financial assistance from NZSEE, through a student research scholarship to the primary author, is gratefully acknowledged. The invaluable assistance of Donato Innamorato and Gianmario Benzoni from the University of California at San Diego in the provision of experimental data is greatly appreciated. 


\section{REFERENCES}

1. To, N. H. T., Ingham, J. M. and Sritharan, S. (2001), "Monotonic Nonlinear Strut-and-Tie Computer Models", Bulletin of the New Zealand Society for Earthquake Engineering, Vol. 34, No. 3, September, pp. 169-190.

2. Innamorato, D., Seible, F. and Hegemier, G. A. (1996), "Full Scale Test of a Two Column Bridge Bent with Carbon Fibre Jacket Retrofit", Report ACTT-96/10, Department of Applied Mechanics and Engineering Sciences, University of California at San Diego, La Jolla, California, August, $80 \mathrm{p}$.

3. Ingham, J. M., Priestley, M. J. N. and Seible, F. (1994), "Seismic Performance of Bridge Knee Joints - Volumn I: Rectangular Column/Cap Beam Experimental Results", SSRP-94/12, Department of Applied Mechanics and Engineering Science, University of California at San Diego, La Jolla, California, June, 227 p.

4. Ingham, J. M., Priestley, M. J. N. and Seible, F. (1997), "Seismic Response of Bridge Knee Joints having Columns with Interlocking Spirals", Bulletin of $N Z$ National Society for Earthquake Engineering, Vol. 30, No. 2, June, pp. 114-132.

5. CEB-FIP, "Model Code for Concrete Structures", 3rd Edition, Comite Euro-International $d u$ Beton/Federation Internationale de la Precontrainte, Paris, 1978, 348 p.

6. Ang, B. G., Priestley, M. J. N. and Paulay, T. (1989), "Seismic Shear Strength of Ciricular Reinforced Concrete Columns", ACI Structural Journal, Vol. 86, No. 1, January/February, pp. 45-59.

7. Collins, M. P. and Mitchell, D. (1997), "Prestressed Concrete Structures", Response Publications, Ontario, Canada, $776 \mathrm{p}$.

8. Rahal, K., N. and Collins, M. P. (1999), "Background to the General Method of Shear Design in the 1994 CSA-AA23.3 Standard", Canadian Journal of Civil Engineering, Vol. 26, No. pp. 827-839.

9. CSA. A23.3-94, "Design of Concrete Structures", Canadian Standards Association, Ontario, 1994, 199 p.

10. Priestley, M. J. N., Seible, F. and Calvi, G. M. (1996), "Seismic Design and Retrofit of Bridges", John Wiley \& Sons, Inc., New York, $333 \mathrm{p}$.

11. Blackman, J. S., Smith, G. M. and Young, L. E. (1958), "Stress distribution affects ultimate tensile strength", ACI Journal, Proceedings, Vol. 30, No. 6, pp. 679-684.

12. Somayaji, S. and Shah, S. P. (1981), "Bond stress versus slip relationship and cracking response of tension members", ACI Structural Journal, Vol. 78, No. 3, pp. 217-225.

13. Chan, H. C., Cheung, Y. K. and Huang, Y. P. (1992), "Crack analysis of reinforced concrete tension members", Journal of Structural Engineering, ASCE, Vol. 118, No. 8, August, pp. 2118-2132.

14. NZS: 3101, "Code of Practice for the Design of Concrete Structures", Standards Association of New Zealand, Wellington, 1995, $264 \mathrm{p}$.

15. Prakhya, G. K. V. and Morley, C. T. (1990), "TensionStiffening and Moment-Curvature Relationship of Reinforced Concrete Elements", ACI Structural

Journal, Vol. 87, No. 5, September-October, pp. 597 605 .

16. Clark, L. A. and Cranston, W. B. (1979), "The Influence of Bar Spacing on Tension Stiffening in Reinforced Concrete Slabs", International Conference on Concrete Slabs, Dundee, pp. 118-128.

17. Clark, L. A. and Speirs, D. M. (1978), "Tension Stiffening in Reinforced Concrete Beams and Slabs under Short-Term Load", Technical Report No. 42.521, Cement and Concrete Association, London, 20 p.

18. Eurocode 2, "Design of Concrete structures Part 1: General rules and rules for buildings", European Committee for Standardization (CEN), EVN 1992-1-1: 1992, 253 p.

19. Benzoni, G., Ohtaki, T., Priestley, M. J. N. and Seible, F. (1996), "Seismic Performance of Circular Reinforced Concrete Columns under varying AxialLoad", Report SSRP-96/04, Department of Applied Mechanics and Engineering Sciences, University of California at San Diego, La Jolla, California, August, 174 p.

20. Vu, N. H. D., Priestley, M. J. N., Seible, F. and Benzoni, G. (1997), "The Seismic Response of WellConfined Circular Reinforced Concrete Columns with Low Aspect Ratios", Report SSRP-97/15, Department of Applied Mechanics and Engineering Sciences, University of California at San Diego, La Jolla, California, June, $69 \mathrm{p}$

21. Priestley, M. J. N., Seible, F. and Benzoni, G. (1994), "Seismic Performance of Circular Columns with Low Longitudinal Steel Ratios", Report SSRP-94/08, Department of Applied Mechanics and Engineering Sciences, University of California at San Diego, La Jolla, California, June, $70 \mathrm{p}$

\section{APPENDIX A - LIST OF SYMBOLS}

$A_{c s}$

$A_{c t}$

$A_{d c s}$

$A_{g}$

$A_{r t}$

$A_{r s}$

$A_{s t}$

$A_{v}$

$A_{\text {ve }}$

$A_{v s}$

$b$

c

$c_{c}$

$C_{c(\max )}$

$d_{b}$

$d_{\nu s} \quad$ diameter of transverse rebars;

$D \quad$ total sectional diameter of the circular sections or total sectional depth of the rectangular sections;

distance from tie member centre to the inner point of plateau of ultimate bond stress area of the longitudinal concrete struts; area of the longitudinal concrete ties; area of diagonal concrete strut; gross sectional area; area of the longitudinal reinforcement ties; area of the longitudinal reinforcement struts; total area of longitudinal tension reinforcement; effective area of transverse tie member in STM; effective shear area;

total area of transverse reinforcement in a layer in the direction of the shear force; total sectional width of rectangular sections; neutral axis depth; concrete coverage to the reinforcement; maximum concrete flexural compression evaluated using section force analysis; diameter of longitudinal rebars; 
D' concrete core diameter measured from centre to centre of peripheral spiral or hoop;

$E_{\mathrm{c}} \quad$ Youngs Modulus of plain concrete;

$E_{\mathrm{s}} \quad$ Youngs Modulus of reinforcement steel bars;

$E A_{e} \quad$ effective axial stiffness;

$E I_{e} \quad$ effective flexural stiffness;

$E I_{g} \quad$ gross flexural stiffness;

$f_{C}^{\prime} \quad$ concrete cylinder strength;

$f_{t}^{\prime} \quad$ plain concrete tensile strength;

$f_{c r} \quad$ crack strength of reinforced concrete;

$f_{c t} \quad$ tensile stress of concrete ties;

$f_{c y} \quad$ effective strength of reinforcement struts;

$f_{d} \quad$ effective strength of concrete struts;

$f_{d t} \quad$ effective strength of concrete ties;

$f_{t y} \quad$ effective strength of reinforcement ties;

$f_{v y} \quad$ tensile strength of transverse reinforcement;

$f_{y} \quad$ measured material strength of longitudinal reinforcement;

$h_{p}$

perpendicular distance between diagonal struts in STM;

$\ell_{t} \quad$ transfer length;

$\ell^{\prime} \quad$ half length of tie members;

$L \quad$ portal frame span;

$n \quad$ ratio of $E_{s} / E_{c}$

$N \quad$ axial compression to the column;

$P \quad$ tension capacity of concrete ties;

$M_{e} \quad$ effective flexural strength;

$M_{y}{ }^{1 s t} \quad$ first yield state moment;

$r_{o} \quad$ radius of circular concrete core measured to the centre line of the longitudinal rebars;

$s$

$s_{L}$

$s_{R}$

reinforcement

s.h.r. strain hardening ratio;

$t \quad$ analogy reinforcement tube thickness;

$u_{m} \quad$ maximum bond stress between concrete and rebar;

$u_{u l t} \quad$ ultimate bond stress between concrete and rebar;

$x_{c} \quad$ compression centroid position at the first yield state;

$x_{t} \quad$ tension centroid position at the first yield state;

$v \quad$ ratio of shear strength (excluding $V_{p}$ ): concrete cylinder strength

$V_{c} \quad$ member shear strength attributed to the concrete tensile capacity;

$V_{p} \quad$ member shear strength attributed to the applied axial load;

$V_{\text {pre }} \quad$ force component of prestress tendon in the opposite direction of the applied shear

$V_{s} \quad$ member shear strength attributed to transverse reinforcement; $\alpha \quad$ half angle of the flexural tension sector.

$\alpha_{N} \quad$ angle between the column axis and the line join the positions of concrete strut at the top and bottom of the column;

$\beta \quad$ factor accounting for the shear resistance of cracked concrete;

$\Delta \quad$ portal frame lateral deflection;

$\varepsilon_{I} \quad$ average principal tensile strain of diagonal concrete;

$\varepsilon_{c t} \quad$ reinforced concrete strain corresponding to $f_{c t}$;

$\varepsilon_{d t} \quad$ reinforced concrete strain corresponding to $f_{d t}$;

$\varepsilon_{x} \quad$ maximum longitudinal reinforcement tensile strain;

$\phi \quad$ half angle of the flexural compression zone;

$\phi_{o} \quad$ effective overstrength factor;

$\theta$ inclined angle between the diagonal struts and the longitudinal axis;

$\rho_{l} \quad$ total longitudinal tension reinforcement area to gross sectional area ratio;

$\rho_{w} \quad$ area ratio of Iongitudinal tension reinforcement to gross sectional area;

$\rho \quad$ area ratio of $A_{r t} / A_{c t}$.

$\sigma_{c t} \quad$ maximum tensile stress of concrete ties;

$\bar{\sigma}_{c t} \quad$ average tensile stress of concrete ties;

$\Sigma_{o} \quad$ is the total perimeter of longitudinal rebar located in the flexural tension zone. 
APPENDIX B - CHARTS OF $\beta$ VALUES

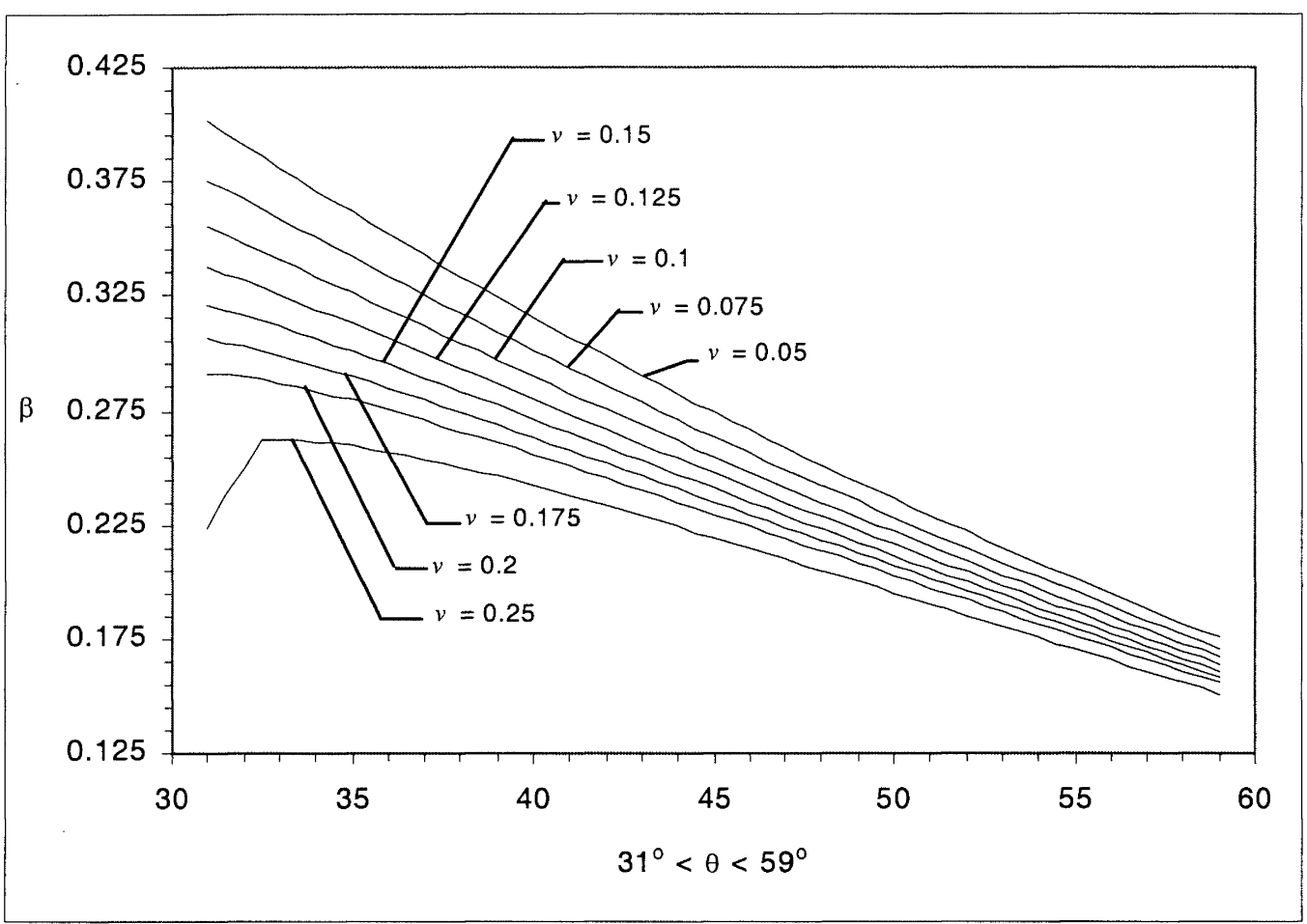

B1) Chart of $\beta$ value for $\varepsilon_{x}=0.0$.

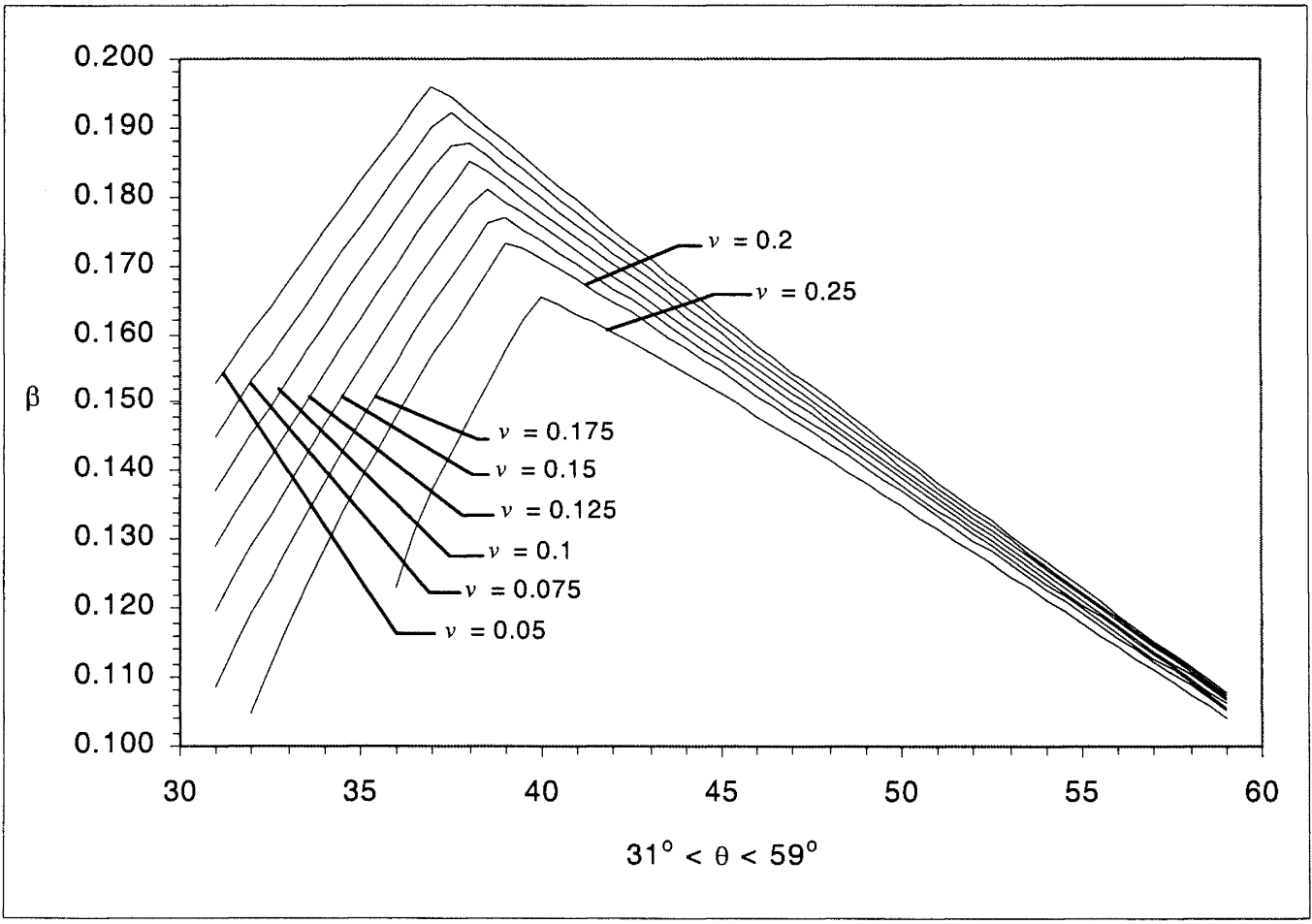

B2) Chart of $\beta$ value for $\varepsilon_{x}=0.001$. 


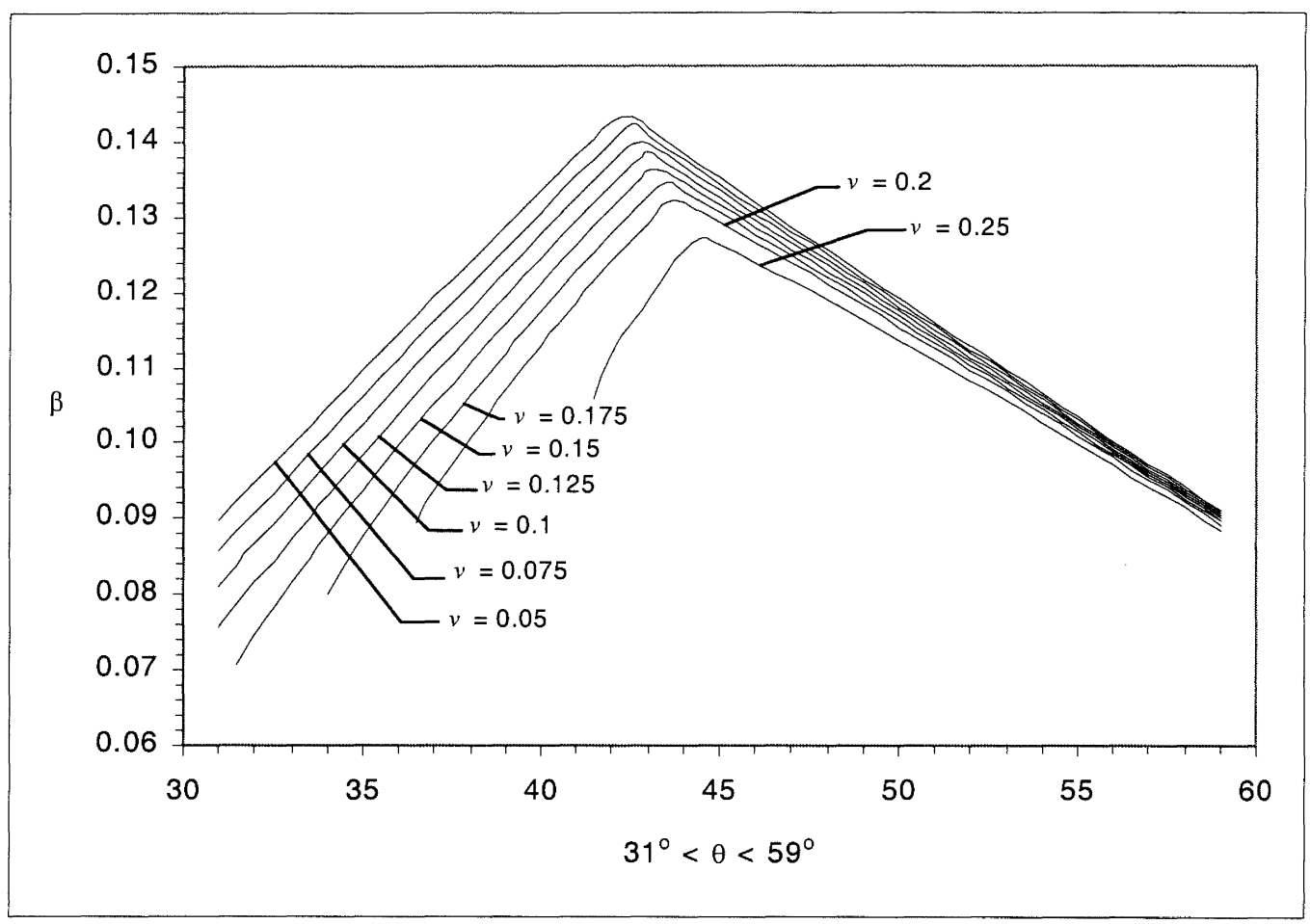

B2) Chart of $\beta$ value for $\varepsilon_{x}=0.002$. 
APPENDIX C - CHARTS OF CONCRETE TIES EFFECTIVE STRENGTH

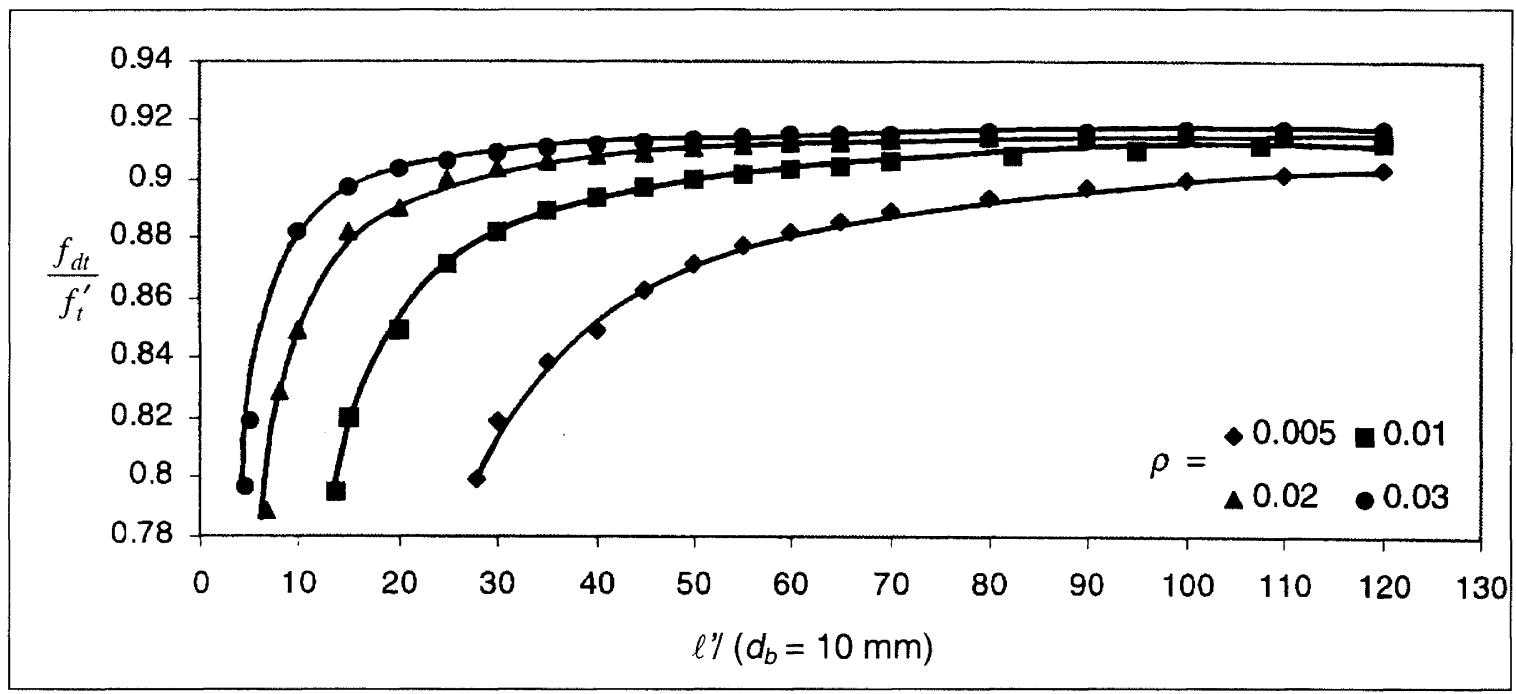

C1) Effective strength of concrete tie for reinforcement size, $d_{b}=10 \mathrm{~mm}$.

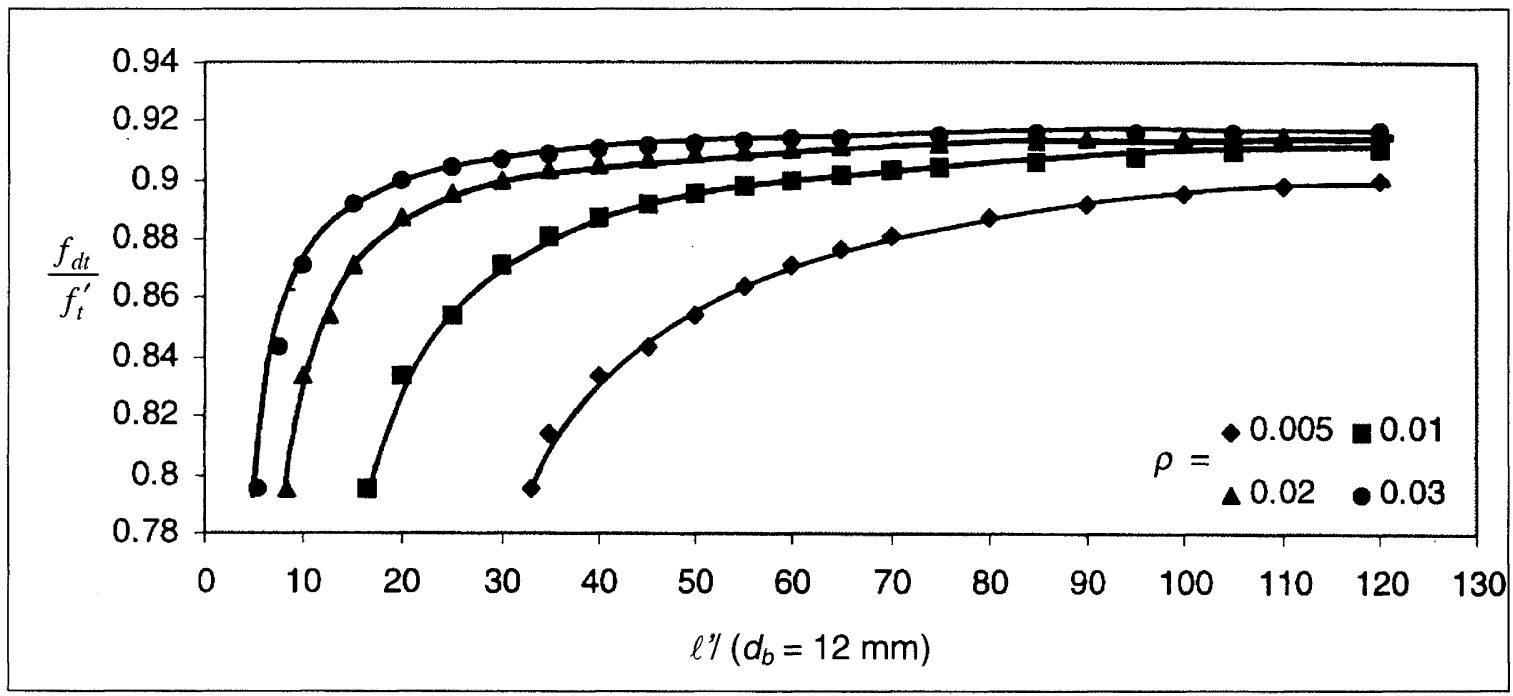

C2) Effective strength of concrete tie for reinforcement size, $d_{b}=12 \mathrm{~mm}$.

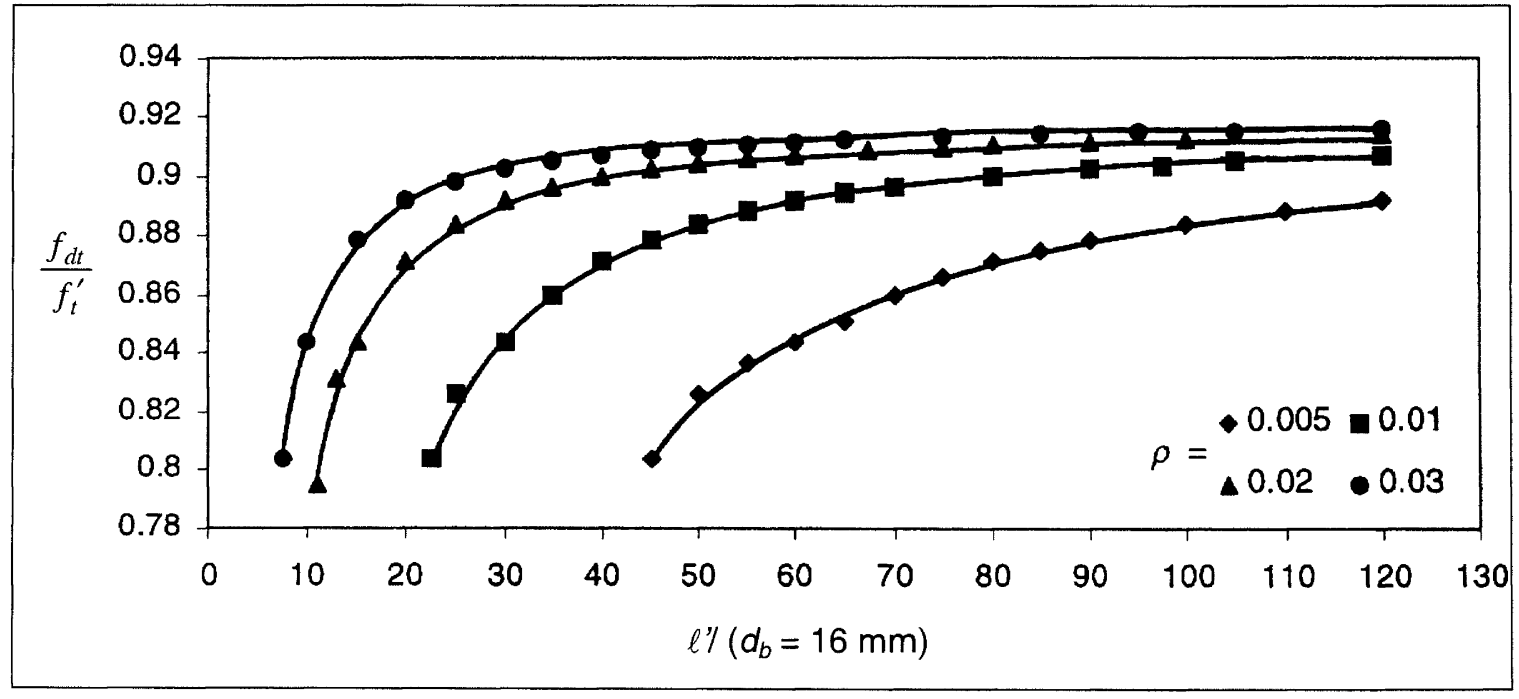

C3) Effective strength of concrete tie for reinforcement size, $d_{b}=16 \mathrm{~mm}$. 


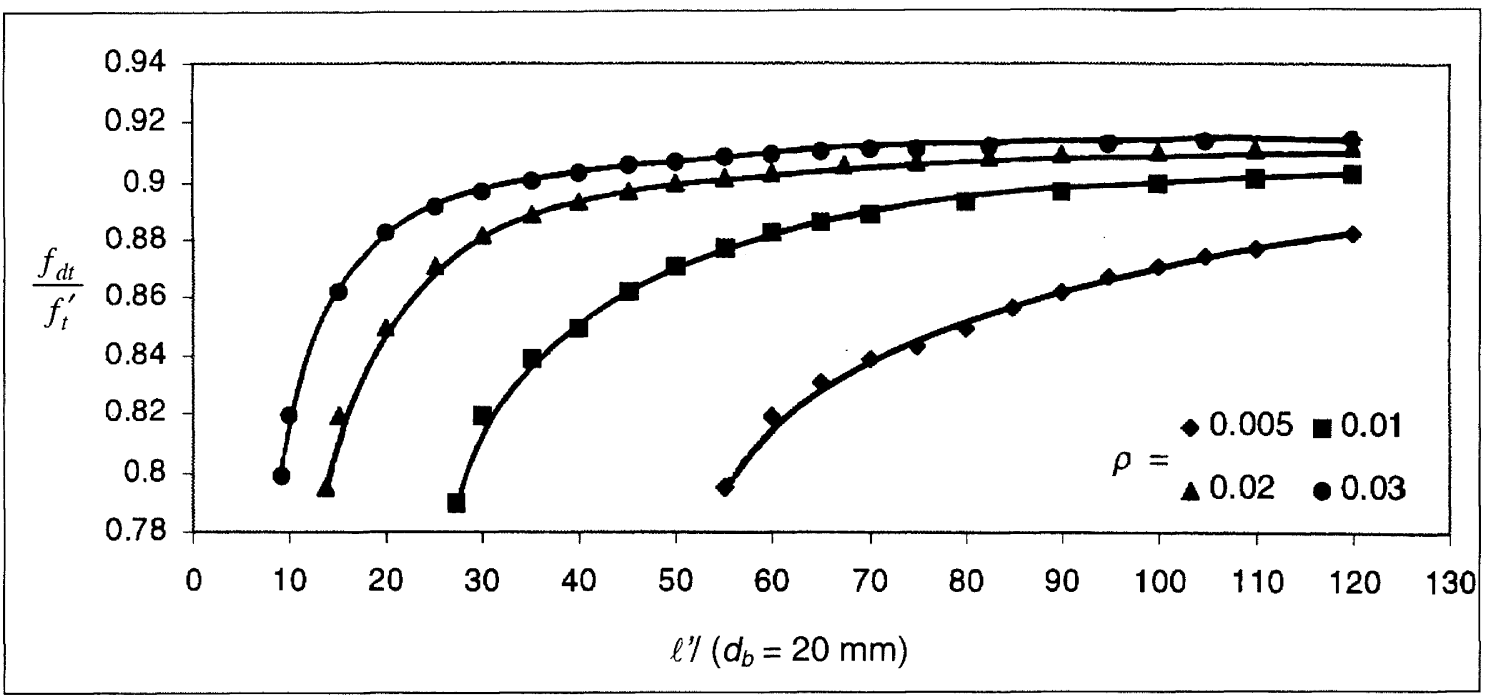

C4) Effective strength of concrete tie for reinforcement size, $d_{b}=20 \mathrm{~mm}$.

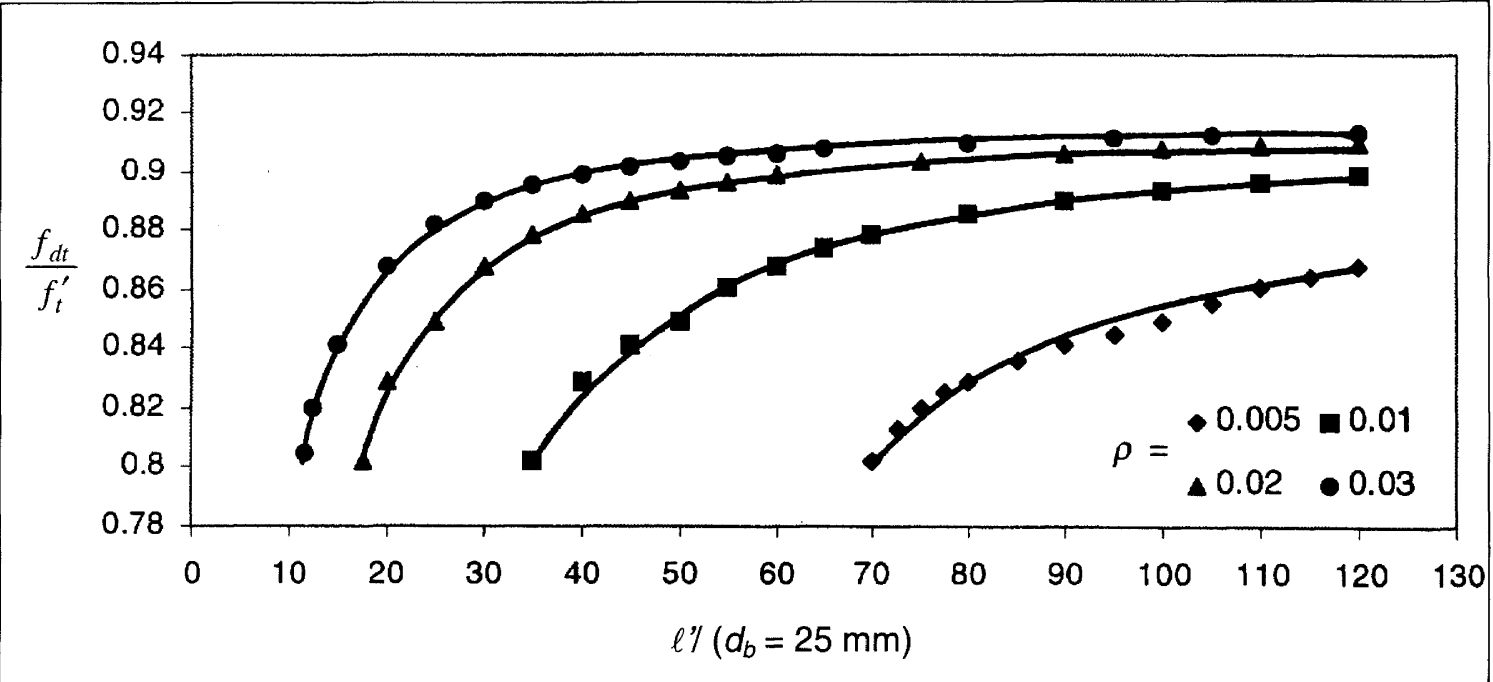

C5) Effective strength of concrete tie for reinforcement size, $d_{b}=25 \mathrm{~mm}$.

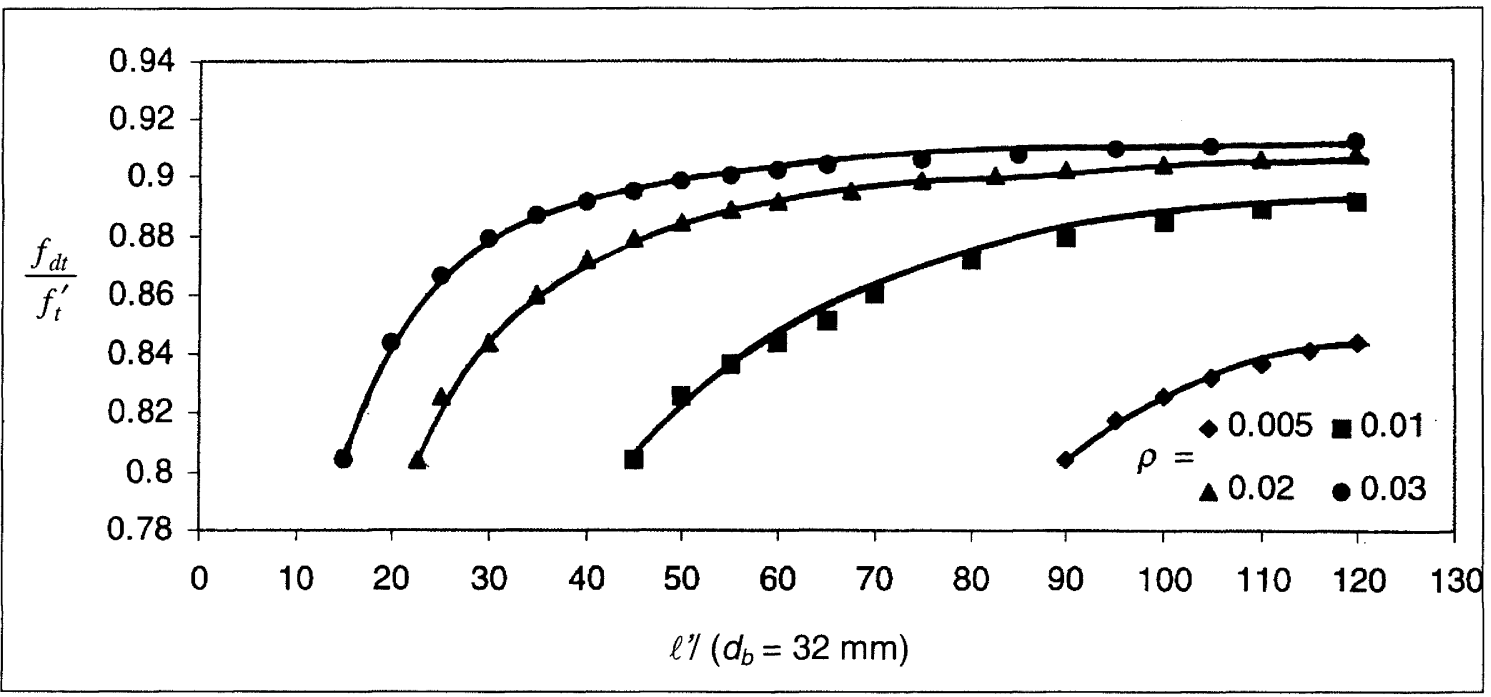

C6) Effective strength of concrete tie for reinforcement size, $d_{b}=32 \mathrm{~mm}$. 


\section{APPENDIX D - SECTION FORCE ANALYTICAL CHARTS}

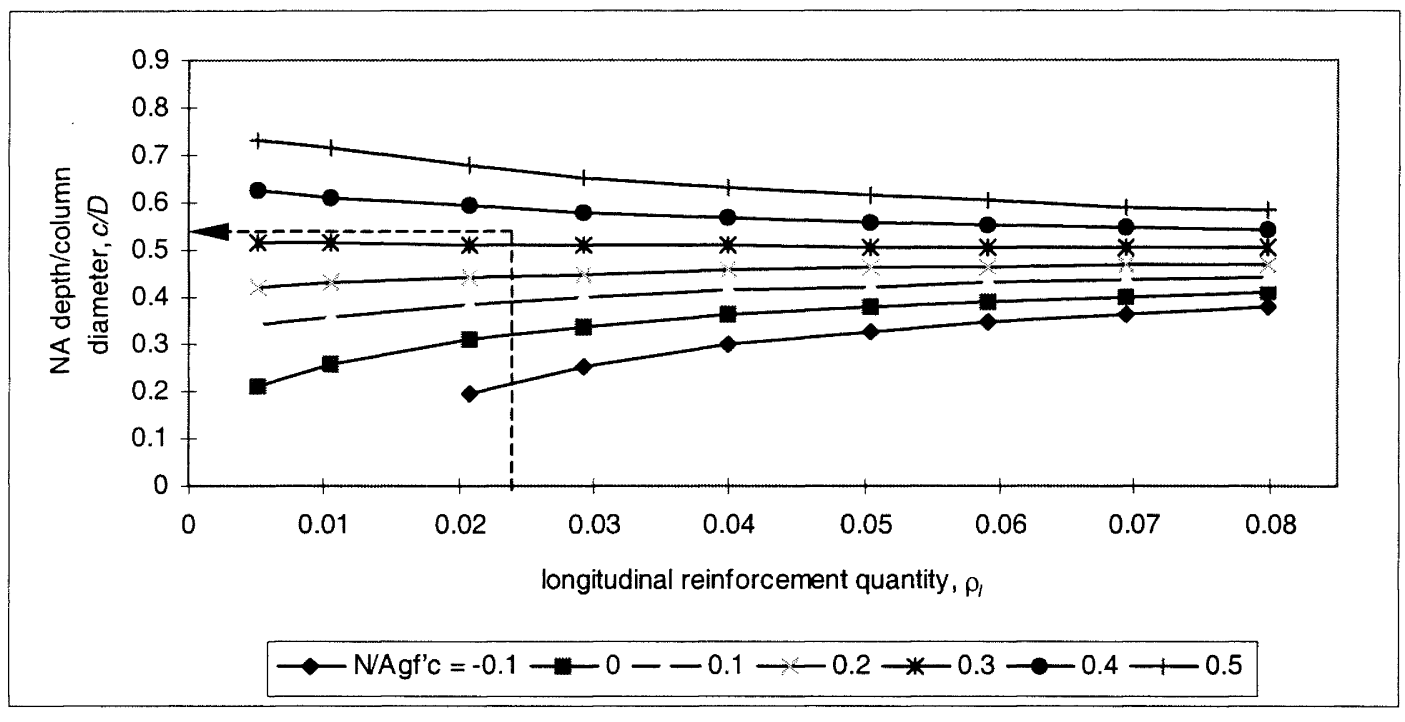

D1) Circular column neutral axis position at the first yield state, $f_{c}^{\prime}=30 \mathrm{MPa}$.

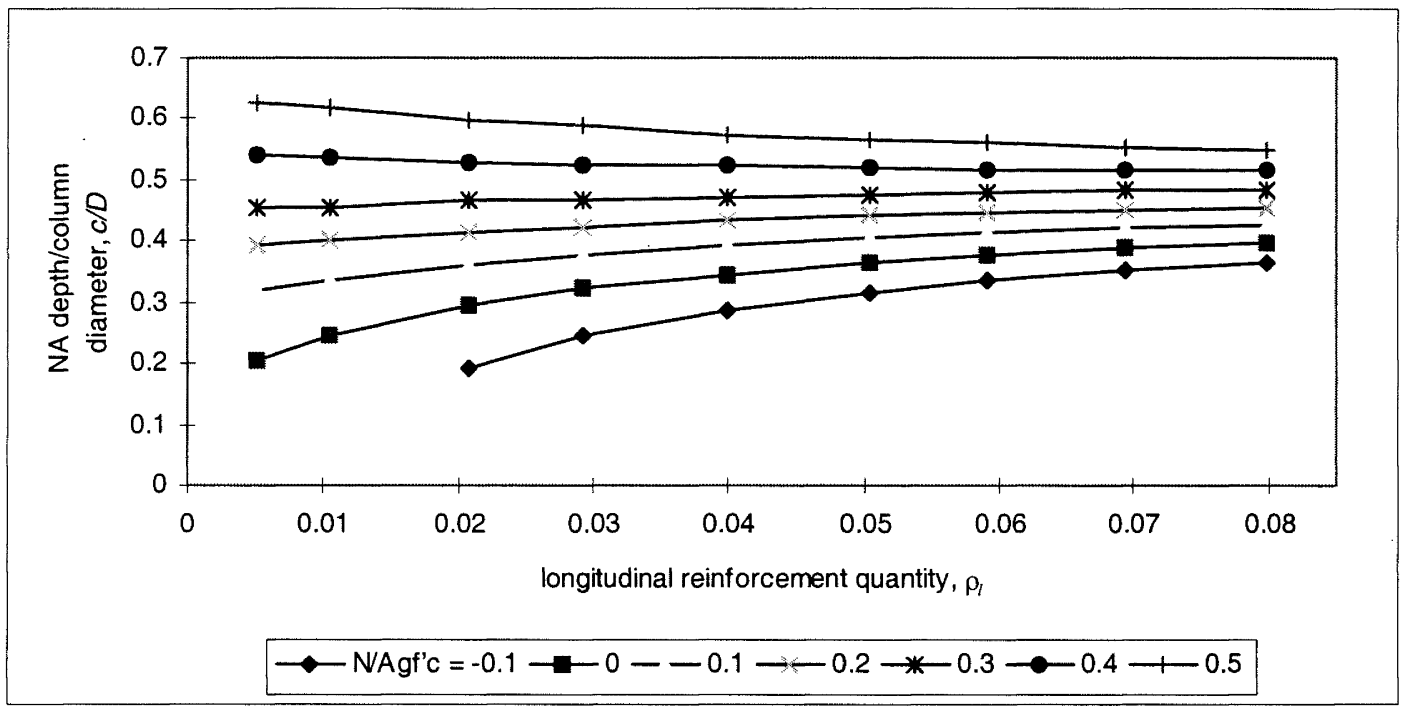

D2) Circular column neutral axis position at the first yield state, $f_{c}^{\prime}=40 \mathrm{MPa}$.

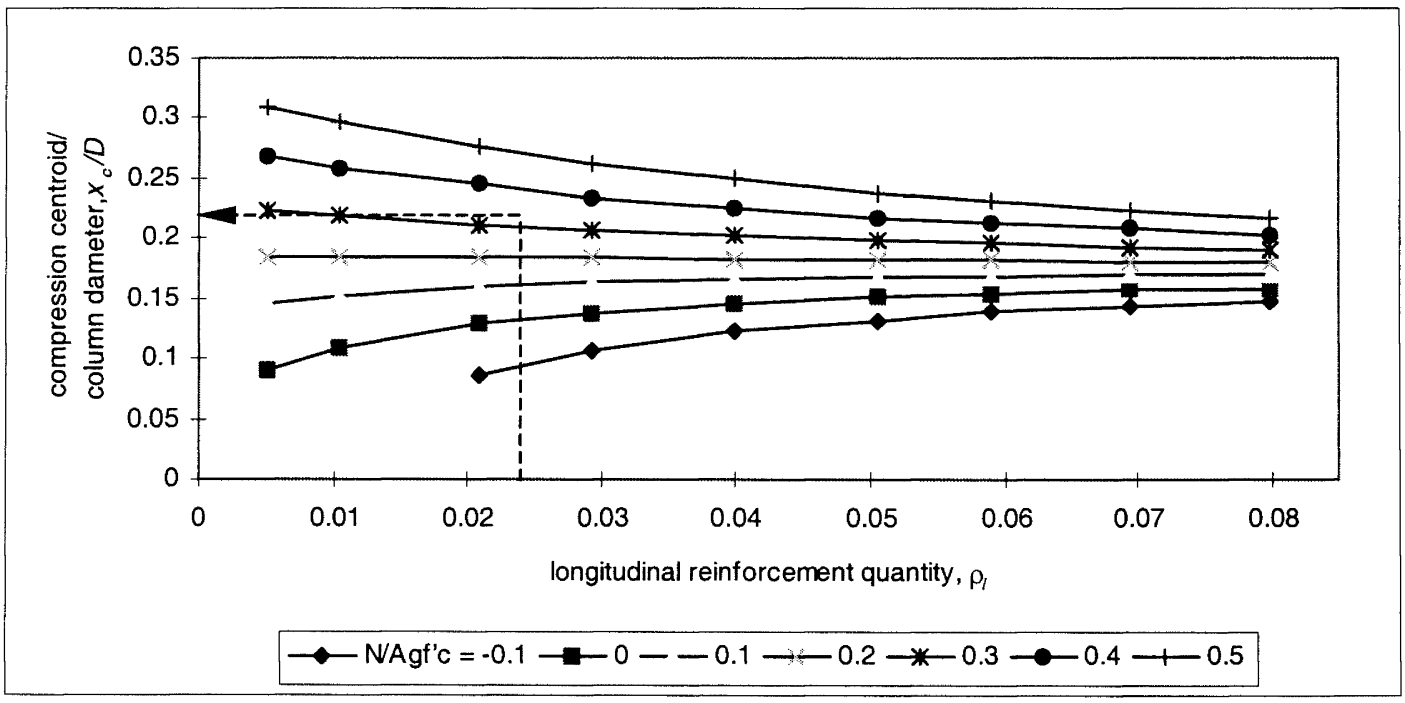

D3) Circular column compression centroid position at the first yield state, $f_{c}^{\prime}=30 \mathrm{MPa}$. 


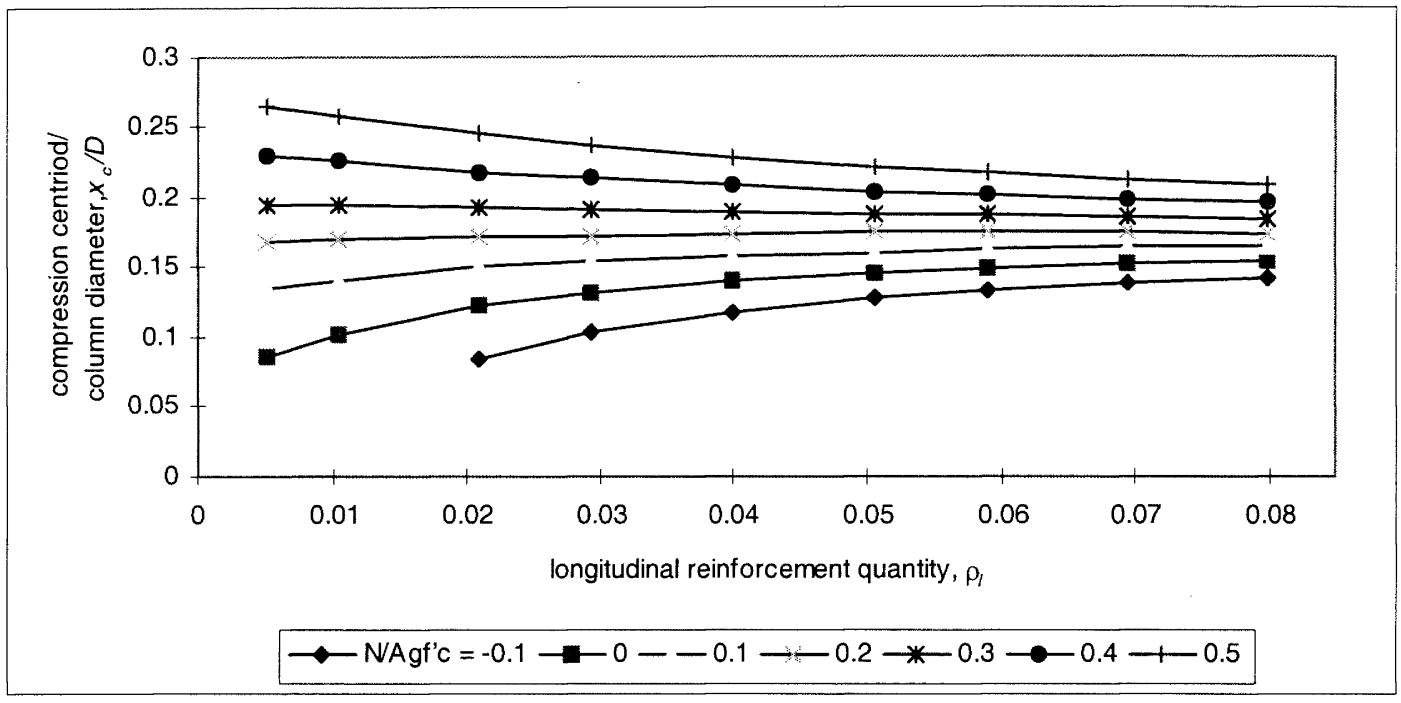

D4) Circular column compression centroid position at the first yield state, $f_{c}^{\prime}=40 M P a$.

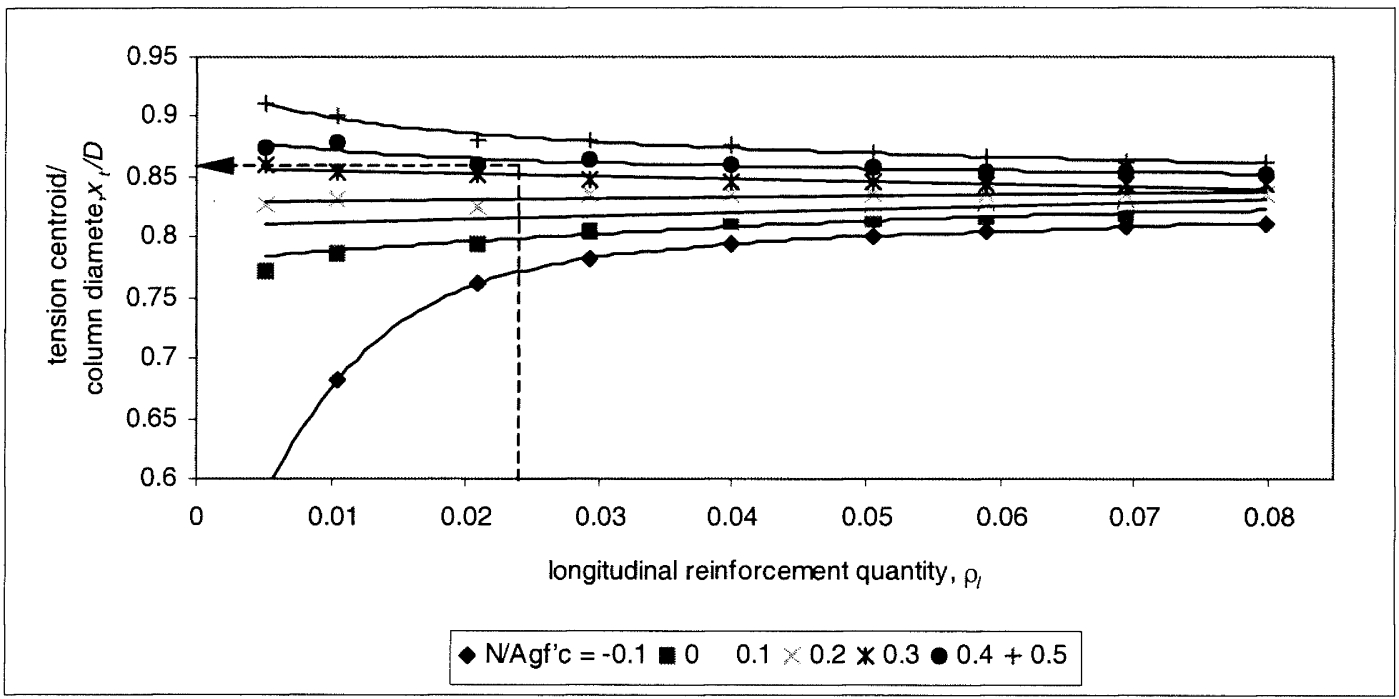

D5) Circular column tension centroid position at the first yield state, $f_{c}^{\prime}=30 M P a$.

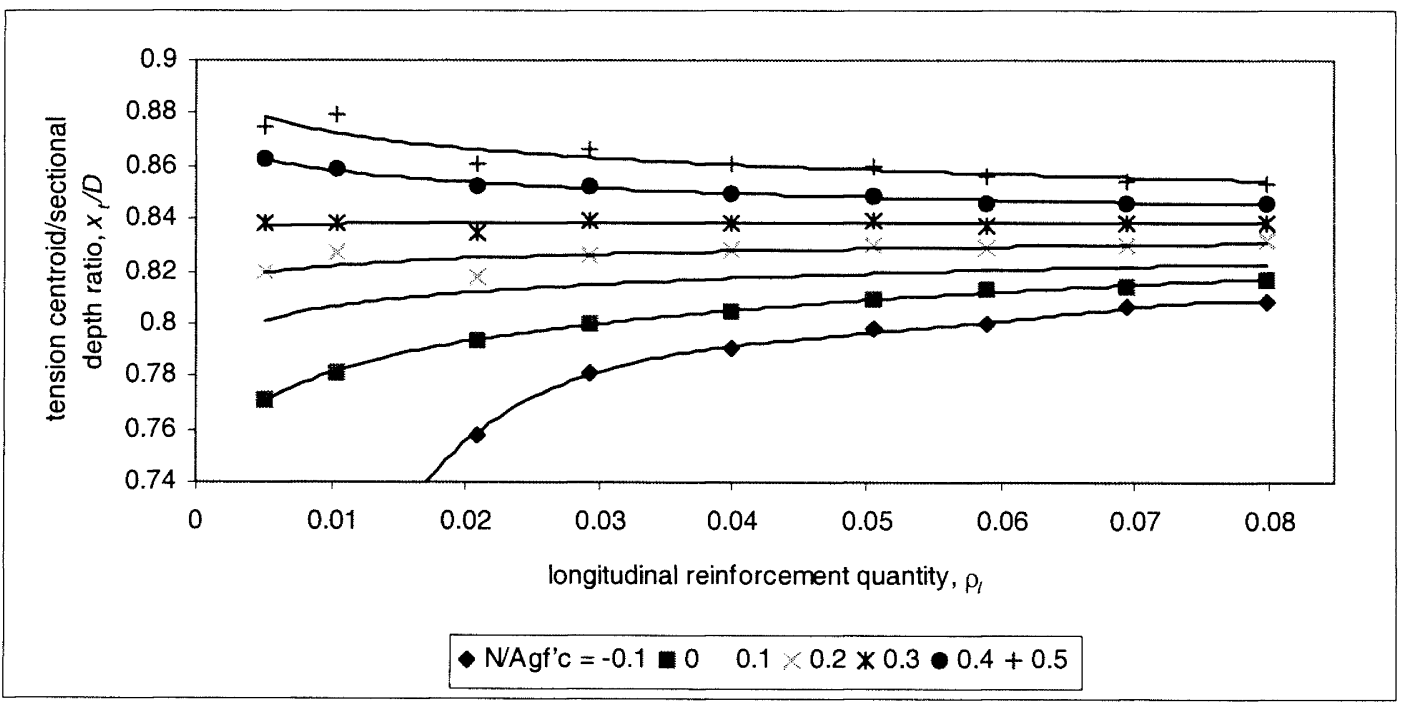

D6) Circular column tension centroid position at the first yield state, $f_{c}^{\prime}=40 \mathrm{MPa}$. 


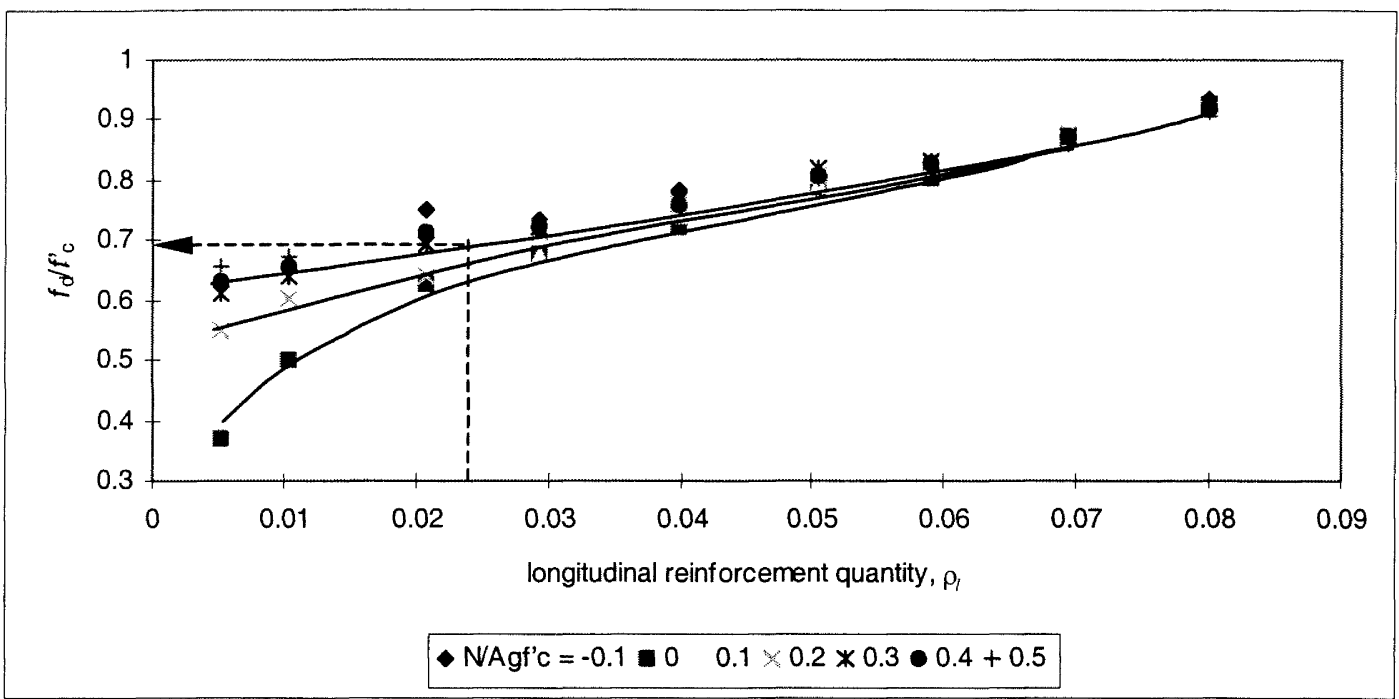

D7) Effective capacity of concrete compression strut in circular column section, $f_{c}^{\prime}=30 \mathrm{MPa}$.

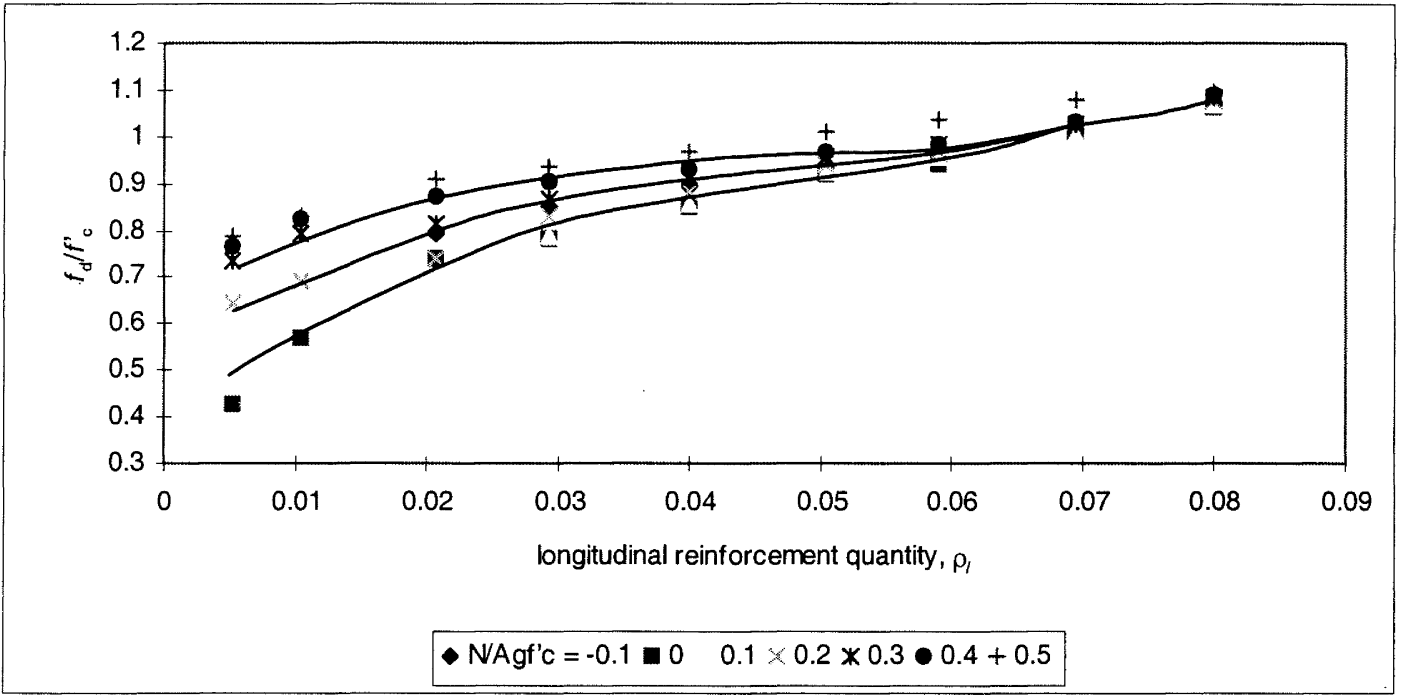

D8) Effective capacity of concrete compression strut in circular column section, $f_{c}^{\prime}=40 M P a$. 